\title{
Eighth International Conference on Emergency Medicine, Boston, Massachusetts, USA, 4-7 May 2000
}

\section{Oral presentations}

Application of the UK A/E Casemix Measure in the year 2000

N F Brayley

The Emergency Department, Colchester General Hospital, Essex

The UK A/E Healthcare Resource Group (HRG) Casemix Measure and its applications are still evolving but HRG casemix returns will be compulsory for all $\mathrm{A} / \mathrm{E}$ departments

This oral presentation explains the scientific basis of the current HRG version based on disposal codes and work in hand to further refine the HRG in six sites in the UK before June 2000.

The refinement sites are studying the impact of the nationally agreed 5 point triage scale, time in the department, and certain procedural cost drivers, for example, thrombolytics and expensive radiographic investigations such as IVU, and computed tomography.

The nationally agreed cost model will be displayed, as will a template spread sheet for calculating prospective payments will be displayed and the implications discussed. HRG profiling can be used for work force planning, identifying service requirements by geographical postcodes, monitoring the changing pattern of referrals to the department by family or general practitioners, monitoring the training and work rate of junior doctors and nurse practitioners.

The limitations of HRGs will also be considered.

Sonoclot coagulation analysis of in vitro dilution of whole blood with colloid and crystalloid solutions

E V Brazil, T J Coats

Academic Unit, Accident and Emergency Department, Royal London Hospital

Introduction-The "Sonoclot analyser" is a device used to measure the quality of a developing blood clot. It measures the changing resistance to movement imposed by a developing clot on a small probe vibrating at an ultrasonic frequency in a coagulating blood sample.

Aim - The study was designed to test the hypothesis that colloid (gelofusine) haemodilution causes a reduction in clot quality measured by Sonoclot analysis compared with crystalloid $(0.9 \%$ sodium chloride) haemodiluted blood. from June 2000

The HRG profiles for different departments

Methods-With local ethics committee approval, each of 12 volunteers had nine fresh blood samples taken from a free flowing upper limb vein and added to solution (colloid or crystalloid) in vitro to make a $10 \%, 20 \%$, $40 \%$, and $60 \%$ solution. One undiluted sample was taken as control.

Results-Rate and peak measurements for control and the various blood dilutions are presented in table 1. There was a highly significant decrease in clot quality for colloid versus crystalloid diluted blood for al haemodilutions.

Conclusion-Blood diluted with gelofusine in vitro causes a reduction in clot quality compared with crystalloid diluted blood.

\section{Part 8 reviews-do we ever learn?}

$\mathrm{J}$ K Gosnold

Accident and Emergency, Royal Hull Hospitals NHS Trust

In 1973 Maria Colwell died at the hands of her mother's violent cohabitee, following seven years of involvement with the local authority social services department, as well as being known to the health visitor and family doctor who both had increasing concern about her health and anxiety being expressed by her school regarding her irregular attendance and failure to learn.

Since then numerous children have died in the United Kingdom in similar circumstances and Statutory Reviews have been held to investigate the events leading up to their deaths-children such as Wayne Brewer, Heidi Cosedhar and Jasmine Beckford.

A decade ago events in Cleveland lead to the Butler-Sloss report and to the requirements for a more formal review procedure under the Child Protection Committee Guidelines and Procedures - the Part 8 review system.

Children still frequently present to accident and emergency (A\&E) departments in the United Kingdom with suspicious injuries or signs of neglect and, in some instances, attend repeatedly with similar, often fallacious, histories of illness that should raise a suspicion of Munchausen Syndrome by Proxy. Sadly the failure of the A\&E to suspect the diagnosis often prevents repeated ongoing trauma to the child and sometimes their death.

This presentation looks at one such similar case in Hull and reviews the process of the subsequent Part 8 review and the findings.

It became clear that, even in a department where child abuse is historically a high profile issue, children can still be failed.

Table 1 Rate and PEAK measurements for control and the various blood dilutions

\begin{tabular}{|c|c|c|c|c|c|c|c|c|c|}
\hline & \multirow[b]{2}{*}{ Control } & \multicolumn{2}{|c|}{$10 \%$ Solution } & \multicolumn{2}{|c|}{$20 \%$ Solution } & \multicolumn{2}{|c|}{$40 \%$ Solution } & \multicolumn{2}{|c|}{$60 \%$ Solution } \\
\hline & & $C R$ & $C O L$ & $C R$ & $C O L$ & $C R$ & $C O L$ & $C R$ & $\mathrm{COL}$ \\
\hline PEAK seconds & 982 & 679 & $1052^{\star}$ & 686 & $1568^{\star}$ & 586 & $1870^{\star}$ & 847 & $2368^{\star}$ \\
\hline Rate & 20.3 & 24 & $19.7^{\star \star}$ & 24.5 & $17.6^{\star}$ & 22.4 & $12.3^{\star}$ & 17.6 & $7.27^{\star}$ \\
\hline
\end{tabular}

$\mathrm{CR}=0.9 \%$ Sodium Cloride, $\mathrm{COL}=$ Gelofusine

${ }^{\star} \mathrm{p}<0.004 .{ }^{{ }^{\star} \mathrm{p}}=0.0371$. Wilcoxon's signed ranks test.
Can single "first responder" units and priority based dispatch produce a significant impact on the outcome of prehospital cardiopulmonary arrest-a cost effectiveness analysis

T B Hassan`, A Wailloo†, T Porter‡, D B Barnett\$

*Department of Accident and Emergency Medicine, Leeds General Infirmary, †University of Leicester, $\neq$ Leicestershire Ambulance and Paramedic Service, \Leicester Royal Infirmary Objective - To evaluate the resource implications of a tiered "all advanced life support" (ALS) response and criteria based dispatch (CBD) system on the short-term outcome of pre-hospital cardiopulmonary arrest (CPA). Design - A cost effectiveness analysis based upon a "before and after" emergency medical services (EMS) model design.

Subjects-An EMS system serving a population of 930000 , all adults (age $>18$ ) suffering non-traumatic pre-hospital CPA in 1995 (before the interventions-model I) and 1997 (after the introduction of single first responder units and a CBI) system-model II).

Main outcome measure - Cost effectiveness based upon survival to discharge from hospital. Results-278 patients suffered a pre-hospital CPA in 1995 of whom 48 were resuscitated to a stable return of spontaneous circulation (ROSC) and there were 15 survivors to discharge from hospital. This compared with 326 patients in 1997, with 56 patients having a stable ROSC and 13 survivors to discharge. Using estimates from a meta-analysis on the impact of increased unit hours, taking into account increasing call volume over the period, model II would provide a marginal increase in survival to hospital discharge ( $4.44 \%$ versus $4.47 \%$, corresponding to a gain of 1.3 life years). The increase in EMS costs was estimated as $f 269214$, of which $f 2238$ was attributed to CPA calls. Including the subsequent $\mathrm{A} \& \mathrm{E}$ and hospitalisation costs for these cases gave an estimated annual increase in costs of $£ 45976$ for CPA cases and a cost effectiveness ratio of $£ 34091$.

Conclusion - Prioritised response (CBD) and introduction of tiered ALS care increased the number of patients requiring ICU care but had no impact on the number of lives saved from pre-hospital CPA. Increased NHS costs were incurred per life year gained.

Right first time-the use of an aluminium filter to improve visualisation of the cervicothoracic junction on the lateral cervical spine radiograph

A MacNamara, S Stevens, P Crowe, J Reynolds

Accident and Emergency Department, Birmingham Heartlands Hospital

Background - In the initial imaging of the cervical spine in the trauma victim the lateral radiograph is the most useful plain radiographic projection. The C7/T1 junction, is often poorly demonstrated because of overlying shoulder musculature. 
Objective-To determine whether the rate of visualisation of C7/T1 can be improved by the use of an aluminium filter and a high $\mathrm{K}-\mathrm{V}$ technique when performing the literal cervical spine radiograph.

Method-An aluminium filter was constructed. A prospective randomised controlled trial was undertaken. The resulting radiographs were assessed blindly by two consultant radiologists. The primary measurement was visualisation of the upper border of $\mathrm{T} 1$.

Results-160 patients were recruited to the study. There was a $32 \%(95 \%$ CI $15.4 \%$, $48.6 \%$ ) increase in visualisation of the C7/T1 junction when using the filter. There was also significant improvement in visualisation of spinous processes and facet joints.

Conclusion-Use of a aluminium filter and a high $\mathrm{K}-\mathrm{V}$ technique greatly increases the rate of visualisation of $\mathrm{C} 7 / \mathrm{T} 1$ on the lateral cervical spine radiograph. The implications of this technique are presented.

The ability of cause of accident to predict psychological outcome among male accident and emergency attenders

S M Mason, J Wardrope, G Turpin

The Accident and Emergency Department, Northern General Hospital, Sheffield

This study aimed to evaluate the effect of actual and perceived cause of injury on psychological outcome.

Male accident and emergency attenders admitted to hospital after accidental injury were prospectively followed up at six weeks, six months and 18 months $(n=210)$. Cause of injury was documented according to the Major Trauma Outcome Study criteria. In addition, details about perceived cause of the accident were recorded such as blame for the accident, involvement of alcohol, others being injured at the time and predictability of the accident. Follow up documented psychological symptoms such as anxiety, depression, post-traumatic stress disorder symptoms and psychiatric caseness.

A relation between psychological outcome, cause and perceptions of the accident were investigated using two tailed Pearson's correlation. Variables relating to cause of injury were subjected to linear regression analysis to evaluate their ability to predict psychological outcome. A relation was found between the development of more severe psychological symptoms and those patients who had suffered certain types of injury. In addition, those patients who believed their accident was not predictable, where others were injured, where alcohol was involved and where patients believed they could have prevented the accident were predicted to have a worse psychological outcome.

These results suggest a relation exists between actual cause of injury, individual interpretations of accidents, and psychological morbidity.

Urban versus rural trauma outcome study

A C McGuffie, G Kerr, D Beard, S C Wilkie, M O Fitzpatrick, C Graham, J Henry, T Parke Western Infirmary, Glasgow

Objective - To compare the outcome of patients sustaining significant trauma in a rural environment with those in an urban environment.

Design-A prospective, observational, multicentre study of the catchment population of a regional neurosurgical centre (2.8 million people) in the west of Scotland.
Methodology-Scottish Ambulance Service population density information was adapted to define urban and rural populations with $>0.5$ persons per acre defined as urban and $<0.5$ persons per acre as rural. Patients who fulfilled the entry criteria of the Scottish Trauma Audit Group were entered into the study. TRISS methodology was then applied to these results. Outcomes were measured in terms of length of hospital stay and mortality Results - A total of 2189 patients have been entered into the study to date with 1848 $(84.4 \%)$ urban and $341(15.6 \%)$ rural. Both groups were comparable in terms of age and sex. There were significantly more cases of penetrating trauma, assaults and low falls than expected in the urban group. All pre-hospital times were significantly longer for rural patients and there were significantly more transfers and late transfers in the rural group The W statistic for blunt and penetrating trauma shows that there is a significant excess of survivors per 100 patients within the urban group that is not demonstrated in the rural group.

Conclusions-There are different patterns of urban and rural trauma. Rural patients take longer to get to hospital and are more frequently transferred. Initial results suggest trend towards a more favourable outcome for urban patients, which, if confirmed on completion of the study, may have implications for the provision of trauma care

The new PEP respiratory monitor in the accident and emergency departmentthe latest answer to a long existing problem

K Murali, C Moulton, D Yates, D Doods ${ }^{\star}$, J Purdy ${ }^{\star}$, B Humphreys ${ }^{\star}$

University Department of Emergency Medicine, Hope Hospital, Salford and ${ }^{\star}$ Faculty of Technology, Bolton Institute, Bolton

Objective - To validate the effectiveness of the new Pyro-electric polymer (PEP) respiratory rate monitor in a clinical setting.

Method-A dual phase validation study of the PEP respiratory rate monitor was carried ou in a clinical setting. A comparison was made between the respiratory rates measured by the PEP monitor and a capnograph (the standard accepted in this study) in the first phase and the monitor, the dedicated observer and a nurse in the second.

Results-The level of agreement between the monitor and the capnograph was $((-2.36$ to +116 breaths $/ \mathrm{min}(\mathrm{bpm})$, correlation coef-

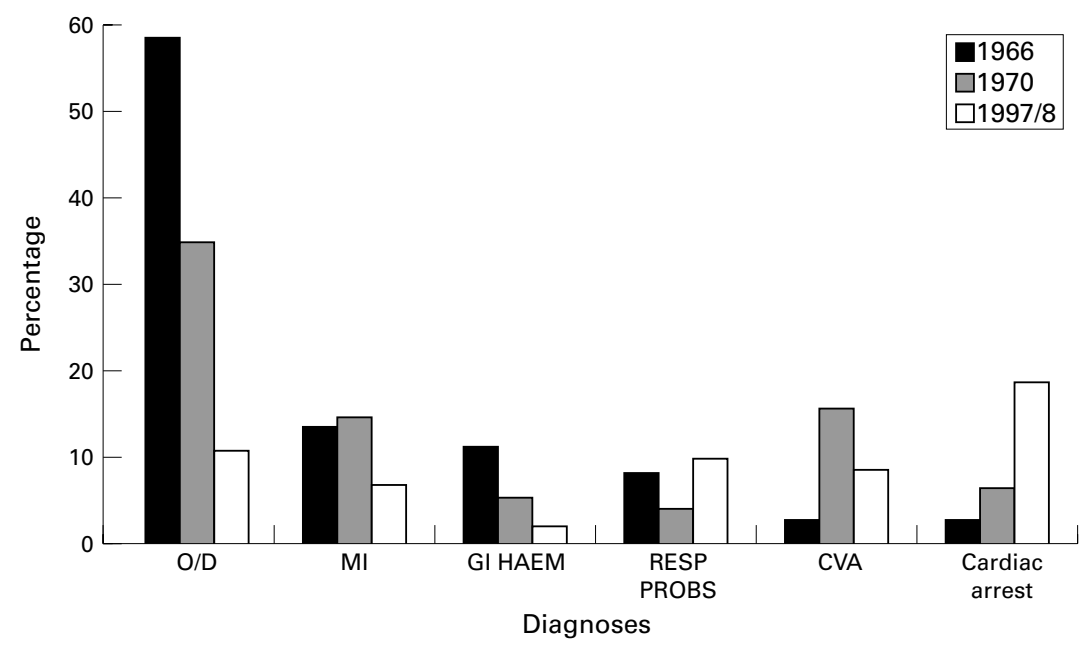

Figure 1 Medical admissions (original diagnosis).

ficient $r=0.98$ ). The level of agreement between the monitor and the dedicated observer was lower at ( $(-3.68$ to $+1.96 \mathrm{bpm})$, $r=0.94)$. The nurse recordings compared with the monitor agreed at $((-8.76$ to $+1.96 \mathrm{bpm})$, $r=0.90)$ and with the dedicated observer at ( $(-8.93$ to $+1.63 \mathrm{bpm}), r=0.89)$.

Conclusion-The PEP monitor compares favourably with the capnograph in the measurement of respiratory rate. The conventional methods of counting respiratory rate do no give an acceptable agreement with the PEP monitor. We believe that the PEP monitor would provide an effective, economical and reliable method of monitoring respiration in non-intubated patients and should therefore supersede the traditional counting of the respiratory rate.

The changing workload patterns in the resuscitation room

B C Paterson, D Coull, C Halliday, C E Robertson

Accident and Emergency Department, Ninewells Hospital, Dundee

This paper quantifies the changing workload patterns in a single urban teaching hospital accident and emergency department by category and diagnosis over the past three decades.

Methods-Three identical time periods were studied for the years $1966,{ }^{1} 1970^{2}$ and 1988 All patients admitted to the resuscitation room were studied.

Results-Medical admissions were found to be increasing significantly. Although all numbers of admissions are up, cardiac arrest is the significant increase (from $2.8 \%$ to $18.5 \%$ ) with significant falls in overdose (58.3\% to $10.6 \%$ ) and gastrointestinal haemorrhage (11.1 to $1.8 \%)$ as a proportion of resuscitation room admissions. (All figures significant at $95 \%$ confidence intervals). Trauma admissions fell significantly as a proportion of admissions (62\% to $28.4 \%$ ) with road traffic acciden victims the largest group in both $1966(61.3 \%)$ and $1997(29.1 \%$ ). (All figures significant at $95 \%$ confidence intervals). Surgical admissions did not increase significantly between 1966 and 1970 but did increase between 1966-1997/8 (2 to $7.4 \%$ ) and $1970-1997 / 8$ (3.8 to $7.4 \%$ ). (Al figures significant at $95 \%$ confidence intervals). Abdominal aortic aneurysm pathology was the largest group (fig 1).

Discussion - This study highlights the majo implications for health care delivery, and associated staffing and service pressures, posed by 
the increasing number of resuscitation room patients.

1 Jenkins AM, McQuillan WM, McNair TJ. Resuscitation room survey. Scott Med f 1969;14:29-35. 2 Baird RN, Noble J, McLean D. Initial intensive care in an accident and emergency department. $B M F 1972 ; 4: 90-2$

The changine ACI-TIPI score and its significance

S S Tachakra

Department of Accident and Emergency Medicine, North West London Hospitals Trust, London and Department of Cardio-vascular Research, New England Medical Center, Boston, USA

The ACI-TIPI (Acute Cardiac Ischaemia Time Insensitive Predicative Instrument) is instrument that uses proven, validated criteria to provide a predictive score of the percentage probability of acute cardiac ischaemia (acute myocardial infarction and unstable angina).

The ACI-TIPI predicative care has been studied before but little is written about the changing TIPI score and its significance.

We studied 830 patients who presented to the emergency department with chest pain. Repeated ECG examinations were a unique feature of this project. We noticed that the TIPI score seemed to increase with a developing myocardial infarction and decreased when a myocardial infarction is treated by thrombolysis. We present an analysis of the 830 cases to see the significance of a changing TIPI score and whether there is any value in performing recurrent ECGs.

The effects of pre-hospital nalbuphine on emergency room analgesia

A P Volans

Accident and Emergency Department, Scarborough Hospital

Nalbuphine is a partial agonist opioid analgesic that has a licence for use by trained paramedic staff in the United Kingdom.

There is a perception that nalbuphine can cause problems with opioid analgesia. A prospective study was carried out of 50 consecutive cases treated with nalbuphine in the field by paramedics working to protocol. Of 50 patients, 45 patients received $10 \mathrm{mg}$ or more of nalbuphine and 39 requested further analgesia once delivered to the department. Remembered pre-injection pain score $(0-5)$ and current pain score were recorded. Overall 26 of $50(52 \%)$ had no improvement in their pain symptoms. Thirty two patients required morphine analgesia given by titrated intravenous injection. Sixteen $(50 \%)$ required over $10 \mathrm{mg}$ of morphine compared with a $10 / 131$ $(8 \%)$ requirement for more than $10 \mathrm{mg}$ morphine during the same period for patients not given nalbuphine.

Supplementary techniques were used to achieve pain relief in 20 patients. It is suggested from observation of the time course and pain reporting that after 30 minutes, 26 of 50 patients were in severe pain and that this pain was made more difficult to treat by the presence of nalbuphine in the system.

Ultrasound imaging of forearm fractures in children

\section{Williamson}

Emergency Department, Frenchay Hospital, Bristol Objective-A prospective study to investigate whether ultrasonagraphy can be reliably used to demonstrate uncomplicated greenstick and torus fractures in children.

Method-Children between the ages of 3 and 16 years with a high clinical suspicion of a non-articular, undisplaced forearm fracture were included. Ultrasound imaging of the injury was performed by a specialist registra in emergency medicine. Standard radiographs of the forearm were then obtained and the patient treated in the normal way. The radiograph was formally reported on at a later date.

Results-There was an absolute correlation between the ultrasound and radiographic findings. The procedure was well tolerated.

Conclusion-Ultrasound seems effective for detecting uncomplicated forearm fractures in children. The procedure is easy to perform and the images easy to interpret.

\section{Poster presentations}

Sports injuries in the western Region of Saudi Arabia

M Z Ansari

City Hospital, NHS Trust, Birmingham

Objective-To evaluate the pattern and causes of sports injuries in the western region of Saudi Arabia, to look at the extent, type of injuries and suggest measures for the prevention of such injuries.

Method-Records of all patients attending an accident and emergency (A\&E) departmen who suffered injuries attributable to trauma were analysed retrospectively. Specifically those with sports injuries. Information regarding age, sex, type of accident, treatment received and outcome was recorded.

Results - Trauma represented $10 \%$ of all referrals to the A\&E department. Sports injuries were recorded in $21 \%$ of patients ( 852 cases) Of 852 sports injuries only $4 \%$ (33) were recorded to be in women. Most injuries were recorded in young males between the age of 11 to 30 years. Injuries of lower limb were found to be commonest, knees $47.5 \%$, ankle joints $23.5 \%$, whereas other sites $29 \%$ (including wrists, elbows, shoulders, spine, legs and muscles). The most commonly practised game causing injury was football in $68 \%$ followed by hand ball $14 \%$. Knee and ankle sprains were the most common injury recorded in $33 \%$ and $27 \%$ respectively.

Conclusion-Sports injuries contribute to nearly $21 \%$ of all $\mathrm{A} \& \mathrm{E}$ attendances attributable to trauma. Lack of physical fitness, inappropriate training and games in imprope fields and sports without sports gear were the commonest facts, so predisposing to injuries.

\section{A five year study of high falls in Edin-} burgh

J P Beale, J P Wyatt, D Beard, A Busuttil, C A Graham

Department Of Accident And Emergency Medicine, Royal Infirmary Of Edinburgh, Scotland

Aim - High falls are a common cause of death and disability. The aim of this study was to obtain an epidemiologically complete picture of all high falls over a five year period in Edinburgh, Scotland.

Method-Prospectively collected data on hospital survivors and hospital deaths were collected from the Scottish Trauma Audi Group database. Revised Trauma Scores were calculated from physiological data at presentation and Injury Severity Scores calculated from the Abbreviated Injury Scale, 1990 revision. Data on the prehospital deaths were obtained from necropsy reports and detailed police enquiry reports.

Results-There were 341 patients in the study, $82 \%$ were male. Some $74 \%$ survived to hospi- tal discharge. Sixty three per cent of the total deaths appeared to be suicides. Head and chest injuries were responsible for the majority of deaths. Pelvis, limb and vertebral injuries predominated in the survivors.

Conclusion-Prevention may be the most effective method of reducing prehospital deaths. Abdominal injuries were associated with a poor outcome and survival may improve with immediate surgical exploration in haemodynamically unstable patients.

\section{Bricks and torture}

P A Bradley, A F Shenton, M Smith, I Butterworth

The new Accident and Emergency Department at Bradford

Bradford's Accident \& Emergency (A\&E) Department in northern England was initially constructed in the 1930s. Until 1999, the department affectionately known as the "shoe box" was housed in a 400 square metre department where we saw 100000 new patients per annum. This paper charts the hurdles, Machiavellian political intrigues, and media manipulation required to bring our plans for a new $A \& E$ department to fruition while working within the confines of the cash constrained National Health Service in England.

The funding was acquired through, brinkmanship, media campaigns, and mastering the arcane art of local politics. Our next challenge was to produce an innovative design for our department, which would not fall foul of the problems encountered by other recently developed units. This required a committed team of local clinicians and architects to produce a novel approach to the design process and some political gymnastics to ensure its implementation.

This paper reveals the truth behind the "roller-coaster ride" faced by the consultants involved in planning our new $\mathrm{A} \& \mathrm{E}$ department and the innovative way these problems were overcome.

Maxillofacial and globe injuries in motor vehicle crashes

C N Brookes $\star$ S Wang

Blackpool Victoria Hospital, Lancashire and

*Trauma Burn Center, University of Michigan, Ann Arbor, Michigan, USA

Improvements in vehicle design have resulted in appropriately restrained occupants having a significantly decreased incidence of facial fractures requiring operative intervention. This is particularly the case if vehicles are equipped with airbags as supplemental restraint systems.

Much of the research regarding the current restraint systems is based though, on analysis of the effects of trauma on crash dummies and cadavers. Unfortunately, "real life" crashes do not always comply to the artificially engineered situations within the laboratory. As a consequence, within North America, the Crash Injury Research and Engineering Network (CIREN) has been established to collect and analyse data on every aspect of the injuries suffered by occupants of motor vehicles in crashes. In addition, the vehicles themselves are examined by expert crash investigators and the occupant's injuries are then correlated to the deformation of the vehicles involved. Finally, the findings are discussed with engineers from the motor manufacturers who have a direct interest in vehicle safety and design. 
A detailed analysis of 20 CIREN cases who presented to a Level One Trauma Centre in North America, between 1996 and 1998, with facial injuries is presented. The aetiology of these injuries is discussed with particular reference to vehicle damage and contact of the occupants with the vehicle interior.

Six of the patients who suffered globe injuries are discussed in detail.

The cases described confirm the importance of patients being fully restrained (wearing a three point seatbelt and positive airbag deployment) to achieve maximum protection to ocular-facial structures in high speed collisions. In addition, my analysis confirms previous evidence that airbags, are necessary and useful adjuncts to three point seatbelts. It is postulated though, that patients of short stature may, in certain circumstances, have their ocular/facial injuries exacerbated by the force of the airbag deployment. Those vehicle occupants who wear eyeglasses appear to be at particular risk.

Finally, the frequency of the "A" pillar and the windshield header as a source of facial injury is emphasised. Vehicle manufacturers may, as a result, need to consider further modifications to vehicle interior design to reduce the risk of injury from this structure.

Quantifying risk in elderly people attending accident and emergency with a fall. Results from the Prevention of Falls in the Elderly Trial (PROFET)

J C T Close, R Hooper, S H D Jackson, E Glucksman, C G Swift

Departments of Health Care of the Elderly, Public Health and Accident and Emergency Medicine, King's College Hospital, London

Falls are a common presenting complaint to accident and emergency (A\&E) departments. (PROFET) is a randomised controlled trial that has shown clear benefit of an interdisciplinary assessment of people aged 65 and over presenting to $\mathrm{A} \& \mathrm{E}$ with a fall in terms of reduction of risk of further falls and preservation of function. ${ }^{1}$ The large number of older people presenting with falls necessitates a high risk referral process.

Using data from PROFET, multivariate analysis of independent variables was undertaken to identify those risk factors predictive of further falls in the one year follow up (table 2).

The variables found to be predictive of further falls are easily identified in the A\&E setting and form the basis of a referral mechanism to evaluate falls in a high risk population.

1 Close, Lancet 1999. The Prevention of Falls in the Elderly Trial

Accidental overdose among injecting drug users in Dublin

K Cunningham ${ }^{\star}$, E Keenan, J Barry, M Cotter, M O'Neill, C Quinn, A Lane, B Smyth AIDs and Drugs Service, Cherry Orchard Hospital, Dublin, Ireland and ${ }^{\star}$ Accident and Emergency Department, Royal Liverpool University Hospital

Study objectives-Accidental overdose is an important contributor to the increased mortality of injecting drug users (IDU). Misuse of prescribed drugs is frequently reported by IDU. We sought to identify the drugs involved in accidental overdose.

Method-IDU were interviewed as part of a follow up treatment study using a structured questionnaire. Details on current drug misuse, current treatment and overdose history were recorded.

Results-310 IDU were interviewed. Some $258(83 \%)$ were currently taking methadone and $162(52 \%)$ were being prescribed othe psychotropic drugs. Current substance misuse was reported by $180(58 \%)$. A history of accidental overdose was reported by $173(56 \%)$, and $82(47 \%)$ of these had not sought medical attention. The drugs most frequently involved were heroin $109(63 \%)$, benzodiazepines 51 $(29 \%)$, methadone $27(16 \%)$ and TCADs 18 $(10 \%)$. Overdose followed misuse of a single substance in $89(51 \%)$ cases. None of the single substance overdoses involved methadone, four $(4 \%)$ involved TCADs and four $(4 \%)$ involved benzodiazepines. By contrast, in multiple substance overdoses, methadone was ingested in $27(37 \%)$, TCADs in $14(18 \%)$ and benzodiazepines in 47 (64\%)

Conclusions - The majority of IDU have experienced at least one accidental overdose, although only half sought medical assistance. The misuse of prescribed substances, including TCADs, frequently contributed to multiple substance overdoses and is of particular concern in view of their high toxicity.

A survey of needlestick injuries in paramedics and technicians in The Wes Yorkshire Metropolitan Ambulance Service (WYMAS)

P Gaffney, T Carrigan, G Johnson*

St fames's University Hospital, Leeds and *Yorkshire Metropolitan Ambulance Service

Objectives-To determine the incidence of needlestick injury in paramedics and technicians, to identify situations in which they are likely to occur and to assess knowledge of hepatitis B vaccination status.

Methods-A two page, "closed", self administered questionnaire was used to collect data The questionnaire was distributed to 349 paramedics and technicians, all employed by WYMAS

Results - 234 adequately completed forms were returned (response rate $67 \%$ ). Fifty nine

Table 2 Predictors of further falls in the absence of intervention

\begin{tabular}{llll}
\hline Variable & Odds ratio & $95 \%$ CI & $p$ Value \\
\hline Falls in previous year: & For every fall \\
$\begin{array}{l}\text { Location of index fall: } \\
\text { Indoors }\end{array}$ & 1.5 & $(1.1,1.9)$ & 0.001 \\
$\begin{array}{l}\text { Able to get up: } \\
\quad \text { No }\end{array}$ & 2.4 & $(1.1,5.2)$ & 0.021 \\
$\begin{array}{l}\text { Alcohol intake: } \\
\quad \text { For increase of 10 units/wk }\end{array}$ & 5.5 & $(2.3,13.0)$ & $<0.005$ \\
$\begin{array}{l}\text { AMT: } \\
\quad \text { For a decrease of one scale point }\end{array}$ & 0.55 & $(0.28,1.1)$ & 0.034 \\
$\begin{array}{l}\text { Admitted: } \\
\quad \text { Yes }\end{array}$ & 0.7 & $(0.53,0.93)$ & 0.012 \\
$\quad 0.26$ & $(0.11,0.61)$ & 0.001 \\
\hline
\end{tabular}

(34.5\%) paramedics and $12(19 \%)$ technicians reported having a needlestick injury. Non-resheathing cannulas (venflons, for example) were responsible for most injuries $(61 \%)$. Only $83(48.5 \%)$ paramedics and 26 $(41 \%)$ technicians always wear gloves when handling needles. Interestingly, $18 \%$ of paramedics and $24 \%$ of technicians stated that they do resheath needles. "Cleaning up", over-filling of sharps bins and needle use in a moving ambulance were considered times of particular risk for needlestick injury. Two paramedic injuries and two technician injuries were caused by needles belonging to the patient (intravenous drug abusers, for example). Twelve $(20 \%)$ paramedics who suffered a needlestick injury stated they did not follow the recommended reporting procedure. Four $(2 \%)$ paramedics and three $(5 \%)$ technicians stated they had not received a course of hepatitis $B$ vaccination. Fifty one per cent of paramedics and $30 \%$ of technicians were unaware of when their next titre check was due.

Conclusions-Needlestick injuries are common among paramedics and technicians. Underreporting appears to be a problem as it is in hospital practice. Certain risky practices have been identified. Uptake of hepatitis vaccination is high. However, knowledge of the ongoing need to have titre checks is inadequate.

Evaluation of the Ottawa knee rules in the accident and emergency department

M B Garrihy, P Doyle, L Narayanaswamy, A J A Morgan, D F Gorman

Accident and Emergency Department, University Hospital Birmingham, Selly Oak Hospital, Birmingham

Nationally and internationally, there is a desire to make appropriate use of investigations.

The Ottawa knee rules (OKR), a set of guidelines for radiography of the acutely injured knee, state that a knee radiograph is only indicated with any of these findings; aged 55 or older, tenderness of the patella, tender head of fibula, inability to flex knee to ninety degrees or inability to weightbear.

This retrospective study reviewed 257 consecutive patients with knee injuries at an accident and emergency department over a three month period. The OKR were applied retrospectively.

One hundred and ten patients met the OKR criteria $(42.8 \%), 82$ of these were radiographed $(31.9 \%)$. One hundred and forty seven patients did not meet the OKR criteria $(57.2 \%), 45$ of these were radiographed $(17.5 \%)$. A total of 18 bony injuries was recorded (7\%), all coming from the group that satisfied the OKR criteria.

In this study the OKR were shown to have a sensitivity of $100 \%$ and a specificity of $73 \%$.

It can be concluded that application of the OKR results in few, if any, missed fractures and results in fewer radiographs being performed. This represents a considerable saving of resources.

\section{The facts of death}

P Gilligan, D Hegarty, C Muldoon, M Smith, B Farrell, E Leen, D Barton

fames Connolly Memorial Hospital, Blanchards-

Introduction - This study was prompted by the common question asked by bereaved relatives, "Doctor, what was the cause of death?". Objective - To identify the aetiology of death in adults brought in dead or dying in an emergency department (ED). 
Methods - A retrospective study of all deaths in the ED of James Connolly Memorial Hospital, Blanchardstown, occurring between 1 January 1998 to 31 December 1998 . The study population included all patients who were confirmed dead in the ED or in theatre having failed to respond to emergency surgery. Postmortem records were analysed from the department of pathology and the Coroner's Office.

Results-During 1998, 104 (0.3\%) patients were pronounced dead in the department or in the emergency theatre. Eighty $(76.9 \%)$ of the deceased underwent postmortem study. There were $20(19.2 \%)$ traumatic deaths and 84 $(80.7 \%)$ non-traumatic deaths. Cardiovascular disease (predominantly ischaemic heart disease and congestive cardiac failure) accounted for the majority of non-traumatic postmortem proven causes of death $(63.3 \%)$. Other nontraumatic causes included; suicide (13.3\%), aortic aneurysm rupture (5\%), pulmonary embolus $(3.3 \%)$ and subarachnoid haemorrhage $(3.3 \%)$. Road traffic accidents accounted for $70 \%$ of traumatic deaths and $13.5 \%$ of total deaths. Serious head injury was recorded in $78.6 \%$ of patients dying in road traffic acccidents. There were also four traumatic suicides. Interestingly, surgical disease accounted for only nine $(11.3 \%)$ of 80 postmortem proven causes of death but accounted for three (43\%) of such deaths in those who were in sinus rhythm on arrival to the ED.

Conclusion-This study may help you counsel the bereaved relatives in EDs, particularly with respect to answering the difficult question of the possible cause of death.

Comparison of insertion of the laryngeal mask and the intubating laryngeal mask by the naive intubator

A Choyce, M S Avidan, C Patel, A Harvey, C Timberlake, N McNeilis, E Glucksman

King's College Hospital, London

Previous studies have shown that unskilled personnel insert the laryngeal mask airway (LMA) more rapidly and reliably than a tracheal tube, and that it provides better ventilation than a facemask. In this study, 75 inexperienced participants were timed inserting the LMA and the intubating laryngeal mask (ILM) in a simulated resuscitation situation using cadavers. Adequacy of ventilation was assessed. Participants were also asked to intubate the trachea via the ILM. The ILM was inserted faster $(p<0.05)$ with a greater proportion achieving adequate ventilation after their first attempt at insertion $(p<0.05)$. Tracheal intubation via the ILM was completed successfully by $67 \%$ (52 of 75 ) of participants. In a questionnaire, participants stated that the ILM was the easier mask to use and the preferred device in an emergency situation. This study does not support the use of the ILM as a conduit for tracheal intubation by the non-anaesthetist; however, the results strongly suggest that practitioners, inexperienced in airway management, should use the ILM rather than the LMA for emergency ventilation.

Rapid sequence intubation in accident and emergency departments in Scotland-preliminary results

C A Graham, S B Thakore, E Docherty, A P Mattick, J Britliffe, M A Johnson, T R J Parke Scottish Trauma Audit Group, Royal Infirmary of Edinburgh

Introduction - In Scottish hospitals rapid sequence intubation (RSI) may be performed by a suitably trained accident and emergency
(A\&E) doctor or by an anaesthetist. Anaesthetic expertise within the training grades of both specialties is variable. This study aims to ascertain if RSI can be performed safely by $\mathrm{A} \& \mathrm{E}$ staff and to compare the outcomes for groups of patients who undergo RSI by different specialists.

Methods-A prospective, multicentre observational study in seven teaching hospitals in Scotland. The study started in January 1999. Results-Of the 229 patients entered into the study in the first six months, $107(46.8 \%)$ were trauma patients, 118 (5 1.5\%) were medical and four $(1.7 \%)$ were "other". A\&E staff performed $126(55.8 \%)$ of first intubations. Training grade doctors performed 180 $(78.6 \%)$ of intubations. There were 129 grade I intubations, 58 grade II, 18 grade III and 8 grade IV (16 missing values). Thirty nine patients had their airway secured on the second attempt and a further five patients required three attempts. There was no statistically significant difference in complication rates between the two specialties.

Discussion - It would seem that appropriately trained A\&E staff can undertake RSI safely on the basis of the first six months of this study. Further evidence will be available as the study progresses and differences in practice between hospitals will be presented.

The association between social deprivation and trauma in Scotland

A Corfield, J Henry, P Grant

Western Infirmary, Glasgow and Western Infirmary, Glasgow/Scottish Trauma Audit Group, c/o Accident \& Emergency Department, Edinburgh Royal Infirmary

Objectives-To investigate possible links between trauma and social deprivation in Scotland.

Design -Prospective observational study, using a national trauma database.

Setting-24 Scottish hospitals covering approximately $98 \%$ of the population.

Participants - The study was conducted over a 29 month period from the 1 August 1996 to 31 December 1998. A total of 14927 patients who fulfilled the Scottish Trauma Audi Group (STAG) entry criteria during this time period were included in the study. Domicile postcodes were recorded from which a Carstairs deprivation category ( 1 most affluent to 7 most deprived were calculated).

Main outcome measures-Mechanism of injury, length of stay, severity of trauma and mortality. Results-13 021 (87\%) patients had Scottish postcodes recorded and were thus assigned appropriate deprivation categories. Some $38.2 \%$ (4791) of patients were in the most deprived group (categories 5, 6, and 7) compared with $32.8 \%$ (1.6 million) of the Scottish population as a whole $\left(\chi^{2}=171.18, \mathrm{p}\right.$ $<0.001)$. Of those sustaining penetrating trauma (626) a higher than expected proportion were from deprivation categories $5-7$ $\left(61 \%, \chi^{2}=145.42, \mathrm{p}<0.001\right)$. A higher than expected proportion of the seriously injured group (ISS 15, 1602 patients) came from deprivation categories $5-7 \quad\left(43 \%, \chi^{2} 18.107\right.$, $\mathrm{p}<0.001)$. Average length of stay and mortality did not differ significantly for any deprivation group.

Conclusions-The socially deprived are more likely to sustain significant trauma in Scotland, and are at greater risk of severe injury. Overall outcomes in terms of mortality however are not adversely affected.
Efficacy of gastric decontamination in paracetamol (acetaminophen) overdose P Gupta, D B Wijetunge, S Premachandran Accident and Emergency, St George's Hospital, London

Aim-To compare the efficacy of gastric lavage and activated charcoal in limiting the absorption of paracetamol in overdose.

Method - In this prospective randomised trial, patients, admitted to the accident and emergency department, four hours of ingestion of more than 5 grams of paracetamol, were allocated randomly in one of the two treatment groups: (1) gastric lavage and charcoal, (2) charcoal only. Plasma paracetamol concentrations were measured before treatment, and after treatment at 60,90 and 120 minutes after the first sample. Rate of fall in paracetamol concentration was used to measure the efficacy.

Results-Of 32 patients, 21 received charcoal, 11 were treated by gastric lavage and charcoal. Plasma concentrations of paracetamol were measured for each group and plotted on a graph. The fall of paracetamol concentrations was found to be greater in the patients treated with charcoal. This was not statistically significant.

Conclusion - Charcoal alone is equally effective as gastric lavage and charcoal in limiting the absorption of paracetamol in overdose within four hours of its ingestion.

A diagnostic care pathway for the management of suspected deep vein thrombosis

K I M Henderson, W Coode

Accident and Emergency Department, Homerton Hospital, London

Suspected venous thrombosis is a common problem presenting to an emergency department. Clinical examination is highly nonspecific but the danger of the diagnosis and the effectiveness of treatment means that any suspicion of venous thrombosis mandates further action. Thus in most series on objective testing, about $75 \%$ of patients do not have venous thrombosis.

In this situation resources are used most efficiently if sensitive tests can be performed as near to the point of presentation as possible. Sensitive tests effectively "rule out" a diagnosis.

We have developed a care pathway that combines a clinical pretest probability score with a physical test for venous occlusion (strain gauge plethysmograph, AMT Venometer) and a haematological marker for the degradation of fibrin clot-D-dimer (SimpliRED). All of these tests can be performed in the emergency department by our own staff. So far we have been able to safely rule out deep vein thrombosis at presentation in 50 of 110 patients. Patients in whom the diagnosis cannot be ruled out are sent for further investigation.

Humanitarian support: designing, building and equipping an emergency department in Kosovo

T J Hodgetts

Accident and Emergency Department, Frimley Park Hospital, Camberley, Surrey

In July 1999 the Specialty Adviser A\&E UK Defence Medical Services was requested by the Department For International Development to design, build and equip a new emergency department for the University Hospital of Pristina, Kosovo. This task was secondary and additional to providing an 
emergency medical service to KFOR troops at 22 Field Hospital RAMC, and to providing life and limb saving resuscitative treatment to the local population. The department was to be situated on the ground floor of an existing block within the 2400 bed complex. This was not only a new department, but also a new specialty for the country. At the time of starting the project the hospital had an unreliable power supply, lacked the ability to dispose of clinical waste, had shortages of basic drugs and medical material, had no effective central administration, and was staffed by volunteer doctors and nurses many of whom had no accredited training.

Using a team of specialist A\&E nurses the Specialty Adviser A\&E provided plans and equipment scales within three days of tasking. Plans retained flexibility, as not all rooms could be examined (not cleared by bomb disposal). Equipment lists were submitted to the Crown Procurement Agency, and drugs lists through Pharmacies Sans Frontières. Local labour was used for the structural development.

The project was completed in six weeks. This paper discusses the problems faced in establishing emergency medicine as a new specialty, and working to ultra-short deadlines to build a new department. The issues of training and sustainability are covered.

\section{"Unexpected" survival from trauma: a} seven year experience

K P G Houlihan, S Gray, J Henry

Accident and Emergency, Edinburgh Royal Infirmary

Aims - To investigate unexpected survivors from trauma and identify key characteristics within the group.

Subjects - Trauma patients presenting to accident and emergency (A\&E) between 1992 and 1998 with a probability of survival (PS) of less than $50 \%$ who survived to discharge.

Methods - Data collected prospectively by the Scottish Trauma Audit Group (STAG) for a single department were analysed. Outcome is determined at discharge, death or three months after admission.

Results-Sixty seven unexpected survivors (median PS 25\%) were identified. The median age was 37 years (range 14-88). Blunt injury accounted for the majority of cases (64, $95.5 \%)$. Fifty six patients $(77.6 \%)$ had been involved in a road traffic accident (RTA). The A\&E Flying Squad (Medic 1) treated 26 patients $(38.8 \%)$. Sixty two patients $(92.5 \%)$ were triaged directly to the resuscitation room. An A\&E consultant was the senior doctor in 39 cases $(58.2 \%)$. Median time spent in A\&E was 70 minutes (range 23-207). Sixty three patients $(94 \%)$ went directly from $\mathrm{A} \& \mathrm{E}$ to a "critical" destination - that is, theatre, ITU or neurosurgery. Median inpatient stay was 38 days (range 6-92).

Conclusions-Most unexpected survivors were young and had been injured in a RTA. Almost all patients were seen in the resuscitation room and over half were treated by an A\&E consultant. There was an $\mathrm{A} \& \mathrm{E}$ presence at scene in over a third of cases. The majority of patients went directly from A\&E to a "critical" destination.

Use of bicycle helmets by children presenting to a paediatric accident and emergency department with a bicycle related injury-implications for injury prevention strategies

P A Leonard, T F Beattie*, D R Gorman†
Accident and Emergency, Royal Infirmary, Edinburgh, ${ }^{\star}$ Accident and Emergency, Royal Hospital for Sick Children, Edinburgh, tLothian Health Board, Edinburgh

Objectives-To establish the safety helmet wearing behaviour of children with bicycle related injuries and investigate the influence of age, sex and deprivation.

Methods-Demographic data on 90 children with bicycle related injuries were collected prospectively and compared with children attending the hospital outpatient department for non-bicycle related problems. A postcode derived deprivation index (DepCat) score was obtained for their place of usual residence.

Results- $64 \%$ of injured children owned a cycle helmet, however only $22 \%$ were wearing it at the time of their injury. Helmet use among controls was greater with $47 \%$ of children wearing their helmet the last time they rode their bike $(p<0.001)$. This difference was found to be confined to children under 8 with $23 \%$ of injured children wearing a helme compared with $68 \%$ of controls $(p=0.0001)$ and was magnified among those children who owned a helmet $(31 \% v 86 \%, \mathrm{p}=0.00001)$ This finding was independent of sex or social deprivation.

Conclusion-Children under the age of 8 who do not wear a helmet are at particular risk of bicycle related injury, especially if they own a helmet. Injury prevention strategies should target these children in particular.

The prevalence of mental health disorder in accident and emergency

A J Lewis, E Glucksman, D Alpers

Guy's, King's and St Thomas's School of

Medicine, King's College London

Much work has been devoted to identifying the levels of emotional disorder in primary care but little work has been carried out looking at emotional disorder in patients presenting to the accident and emergency (A\&E) department, particularly those presenting with minor complaints. We examined with self rating questionnaires 550 patients presenting to the Department of Accident and Emergency at King's College Hospital who were triaged to green and blue categories of the Manchester Triage Scale. The questionnaires used were the 12 point and 28 point versions of the General Health Questionnaire, and the Hospital Anxiety and Depression scale.

Preliminary results indicate $42 \%$ of the sample suffering from an emotional disorde according to the GHQ-12 (cut off score 3) and $31 \%$ according to the GHQ-28 (cut of score 9). Using the $\mathrm{HAD}, 45 \%$ were at high risk of suffering from and anxiety disorder and $22 \%$ at high risk of suffering from a depressive disorder when including probable and definite cases (cut off score 8). In terms of service usage, those who had a positive rating on one or more of the above rating scales had a significantly higher use of the $\mathrm{A} \& \mathrm{E}$ services when measuring attendance.

Table 3

\begin{tabular}{lll}
\hline & Control $(n=177)$ & Intervention $(n=147)$ \\
\hline Sex ratio $(\mathrm{M}: \mathrm{F})$ & $97: 80$ & $72: 75$ \\
Age range $(\mathrm{Median})$ & $1-13(9)$ & $1-13(9)$ \\
Percentage radiographed & $82 \%$ & $81 \%(\mathrm{NS}, \mathrm{p}=0.865)$ \\
Satisfied OAR and radiographed & $96 \%$ & $95 \%(\mathrm{NS}, \mathrm{p}=0.571)$ \\
Radiographed but did not satisfy OAR & $34 \%$ & $31 \%(\mathrm{NS}, \mathrm{p}=0.794)$ \\
Satisfied OAR and had a fracture & $28 \%$ & $24 \%(\mathrm{NS}, \mathrm{p}=0.397)$ \\
Did not satisfy OAR but had a fracture & $7 \%$ & $0 \%(\mathrm{NS}, \mathrm{p}=1.0)$ \\
\hline
\end{tabular}

Sensitivity: $98 \%$. Specificity: $18 \%$ (assumes no missed fractures in the patients radiographed.

Evaluation of the Ottawa ankle rules for the use of radiography in acute ankle and midfoot injuries in children

V Machin, R Hooper, J Glasgow, E Glucksman

Department of Accident and Emergency Medicine, King's College Hospital. London and The Royal Belfast Hospital for Sick Children. Belfast Objectives-To evaluate the Ottawa ankle rules for radiography in ankle and midfoot injuries in children.

Methods-The notes and radiographs of al children of 13 or under presenting with an ankle or midfoot injury to the accident and emergency departments of King's College Hospital and the Royal Belfast Hospital for Sick Children during a two month period were collected and analysed. All clinicians were given a teaching session and a help sheet on the use of the Ottawa ankle rules (OAR) then the audit was repeated for the notes from the subsequent two months.

Results-Table 3 gives the results.

Conclusions-These results suggest that the OAR can be applied safely, in children, as the sensitivity is high and fractures are unlikely to be missed. Over $30 \%$ of children who did no satisfy the criteria were radiographed so there is also potential to reduce the number of radiographs performed and so improve the specificity

A comparison of Steristrips versus glue for the closure of lacerations in a paediatric accident and emergency department A Mattick ${ }^{\star}$, G R Clegg, T F Beattie, T Ahmed

${ }^{\star}$ Royal Infirmary of Edinburgh and Royal Hospital for Sick Children, Edinburgh

Objective-To determine whether Dermabond, is a viable alternative to Steristrips in the closure of children's lacerations.

Methods-Children aged between 1 and 14 years with simple lacerations less than five centimetres long were randomised to closure using Steristrips or Dermabond. Parents, and the nurse treating the child, gave their assessment of treatment using a Visual Analogue Score (VAS). Photographs of the wound taken at presentation and at follow up were graded by a plastic surgeon. Parents also scored the cosmetic results. Complications were noted.

Result - 44 lacerations were studied, 26 closed using Steristrips and 19 with Dermabond. No differences were found in demographic or wound characteristics between groups. Mean VAS scores were compared using a WilcoxonMann-Whitney ranks test. No differences were found in parental scoring of application $(94 \%$ versus $89 \%)$ or cosmetic results $(79 \%$ versus $78 \%$ ) with Dermabond and Steristrips respectively. The nursing staff and the reviewing plastic surgeon recorded no difference in ease of use $(88 \%$ versus $90 \%)$ or cosmesis score $(83 \%$ versus $82 \%)$. The failure rate was similarly low in both groups. 
Conclusion-Simple wound repair in children is equally effective using Dermabond or Steristrips.

The Waterford Prognostic Scoring System for soft tissue sports injury to the knee joint-a pilot study

B Mc Cann Royal Liverpool University Hospital

Objective-To devise a scoring system for sporting injuries to the knee, which could be used in the emergency department to identify those patients who would return to pre-injury sporting level within eight weeks.

Methods-All knee injuries over a three month period were allotted a score based on 27 variables-derived from age, surface type, history of injury, symptoms and clinical examination findings. Patient outcome at eight weeks was gauged simply by return to competitive sport versus persisting morbidity.

Results-39 knees were reviewed. Eighteen were "back to sport" within eight weeks (mean score 6.38 (SD 2.38)), 21 remained "injured" (mean score 13.28 (SD 2.88)). The final score in these groups was proved to be highly significant $(p<0.0001)$. Moreover, using only 5 of the 27 variables - surface type, loaded twist, swelling (as a symptom), positive Lachman test and presence of an effusion - the system retained a high degree of specificity.

Conclusions-Using the system, the emergency physician can predict the outcome of sporting injury to the knee joint in terms of return to competitive sport within eight weeks versus persisting morbidity. The system can be used to reassure on the one hand, and on the other increase the import of early orthopaedic evaluation for the "injured" group.

Accidental hypothermia: the effects of rewarming on plasma $\mathrm{pH}$, ionised calcium, ionised magnesium, and serum parathyroid hormone

J J McInerney, B Breakell, W Madira, T Davies, P A Evans

Accident and Emergency Department, Leicester Royal Infirmary

Background-Accidental hypothermia though uncommon, is associated with appreciable mortality, and the underlying physiological mechanisms remain obscure. Alterations in divalent cations are found in other forms of injury and this study was instigated to evaluate the changes that occur in $\mathrm{pH}$, ionised calcium, ionised magnesium, and parathyroid hormone (PTH) during rewarming.

Methods-Patients were rewarmed with warm blankets and pre-warmed crystalloid fluid. Venous samples were collected at presentation, during rewarming, and at 24 hours.

Findings - Plasma $\mathrm{pH}$ followed a biphasic pattern in all patients $(p<0.001)$, remaining persistently low until core temperatures exceeded $32^{\circ} \mathrm{C}$ after which $\mathrm{pH}$ rose steadily to normal. Ionised calcium and magnesium levels fell as

Table 4

\begin{tabular}{llll}
\hline & Patients admitted & $\begin{array}{l}\text { Median in minutes } \\
\text { interquartile range }\end{array}$ & $\begin{array}{c}\text { Per cent }<120 \\
\text { minutes }\end{array}$ \\
\hline $\begin{array}{l}\text { Decision time } \\
\text { A\&E clinician }\end{array}$ & 34 & $47.5(25.0-80.0)$ & \\
$\begin{array}{l}\text { On call medical team } \\
\text { p value }\end{array}$ & 142 & $150.0(108.8-210.0)$ & \\
$\begin{array}{l}\text { Trolley time } \\
\text { A\&E clinician }\end{array}$ & & $<0.0001$ & \\
$\begin{array}{l}\text { On call medical team } \\
\text { p value }\end{array}$ & 34 & $130.0(103.8-150.0)$ & 41.0 \\
\hline
\end{tabular}

${ }^{\star}$ Mann-Whitney U test $(\mathrm{z}=7.510, \mathrm{p}<0.0001) .{ }^{\star \star}$ Mann-Whitney $\mathrm{U}$ test $(\mathrm{z}=7.054, \mathrm{p}<0.0001)$. patients were rewarmed; below $32^{\circ} \mathrm{C}$ both $\mathrm{p}=0.0488$ respectively), while above $32^{\circ} \mathrm{C}$ only ionised calcium correlates significantly with $\mathrm{pH}(\mathrm{p}=0.0494, \mathrm{p}=0.1656$ respectively). The normal physiological relation between PTH and ionised calcium is dependent on presentation temperature. At temperature below $32^{\circ} \mathrm{C}$ high PTH levels were concurrent with high levels of ionised calcium $(\mathrm{p}=0.0041)$.

Interpretation-During rewarming significan changes in $\mathrm{pH}$ homeostasis occur with associated alterations in ionised calcium and magnesium. Apparent loss of the normal physiological relation between PTH and ionised calcium occurs below $32^{\circ} \mathrm{C}$.

A comparison of medical admissions by an accident and emergency clinician and an on call medical team

R Murphy*, C Eckersley†, P Driscoll

${ }^{\star}$ Accident and Emergency Department, Trafford General Hospital, Manchester, tEffective Practice Unit, Trafford General Hospital, Manchester, $¥$ Accident and Emergency Department, Hope Hospital, Salford

Objectives-To compare the accident and emergency (A\&E) times of medical patients admitted by an A\&E clinician with those admitted by an on call team. To compare the times spent waiting for a bed with the two hour standard recommended in the NHS Patients Charter.

Method -A retrospective data collection of medical patients presenting at A\&E in Trafford General Hospital over a six week period. Patients seen by the A\&E staff grade are admitted directly. Patients seen by the rest of the $\mathrm{A} \& \mathrm{E}$ team are referred to the medical team on call. Time from triage to a decision on admission and total trolley time in $\mathrm{A} \& \mathrm{E}$ were recorded.

Results-Table 4 gives the results. Presentation times, diagnoses and lengths of hospital stay were comparable in both groups.

Conclusions-Medical patients take up a large amount of time, personnel and trolley space in $\mathrm{A} \& \mathrm{E}$ departments. A\&E times are reduced and NHS Patients Charter standards are more often met when $A \& E$ clinicians admit medical patients.

Pre-tibial lacerations-mechanisms of injury and possible preventative measures

J J O'Donnell, P Leonard

Accident and Emergency Department, Royal Infirmary of Edinburgh

Aim-The aim of our study was to look for possible preventative measures in the causation of pre-tibial lacerations presenting to our accident and emergency (A\&E) department.

Methods-Using a questionnaire format completed by the attending physician, we prospectively examined the circumstances surroundcorrelate with change in $\mathrm{pH} \quad(\mathrm{p}=0.0005$, ing 101 consecutive pre-tibial lacerations that presented to our A\&E department.

Results - The majority of patients were female $(82 \%)$ and elderly with $65 \%$ over the age of 65 . In most cases $(85 \%)$ the pre-tibial injury was their only injury. Some $44 \%$ of patients had sustained their injuries at home or in the garden, $18 \%$ sustained their injuries on public transport, in particular while getting on to buses or into taxis and $6 \%$ occurred at work. The remainder occurred in a variety of public places. Fifty per cent of injuries were as the result of a fall or trip, $31 \%$ involved striking the shin against a stationary object and $11 \%$ occurred when a moving object struck the shin. A large variety of objects were implicated in the injury, in only $22 \%$ of cases was the object a step, in $12 \%$ a seat and in $11 \%$ the ground.

Discussion - The majority of pre-tibial lacerations occur at home in the elderly population as a result of simple falls. Some possible preventative measures are discussed including changes to the steps on public buses and the doors of taxis.

The Alcohol Wake-Up Study-a randomised controlled trial evaluating an infusion of potassium, insulin and glucose as a treatment for reversing the effects of intoxication with alcohol

H D M Poncia, P Ransom, J Ryan

Royal Sussex County Hospital, Brighton

Introduction-There are to date no effective "amethystic agents" for acute alcohol intoxication. This study evaluates one proposed treatment

Aims - To evaluate the effect of an infusion of potassium, insulin and glucose on Glasgow Coma Scale (GCS) in patients acutely intoxicated with alcohol.

Methods-This was a prospective, randomised, double blind controlled trial. Inclusion criteria were : a GCS of 12 or less, alcohol as cause of acute intoxication, normoglycaemia and age 18 to 65 years. Exclusion criteria were evidence of head injury, focal neurological signs or pregnancy. Patients received either an infusion of $1000 \mathrm{ml}$ of $10 \%$ dextrose containing $20 \mathrm{mmol}$ potassium and 20 units of Actrapid insulin over one hour or 1 litre of $0.9 \%$ normal saline. GCS was measured hourly. The time taken for GCS to reach 15 was measured. Serial measurements of blood alcohol concentration, glucose, electrolytes and toxicology screening were made.

Results and Conclusions-Detailed results from 80 patients recruited into the study will be available at the conference. A mixture of intravenous potassium, insulin and dextrose may be an effective agent in reversing the effects of alcohol toxicity.

Headaches: can we improve our assessment and management?

L Somers ${ }^{\star}, \mathrm{P}$ Thompson, R Brown

*University Hospital Lewisham, London and King's College Hospital, London

Introduction-Headaches remain a common presenting complaint to accident and emergency $(A \& E)$ departments. A careful history is the key to diagnosis. We have evaluated our assessment of patients presenting with headache and have established a proforma to assist and improve our initial diagnosis and management. We aim to introduce agreed treatment protocols for the health region and are in the process of developing a scoring system.

Methods-A retrospective analysis of all nontraumatic headache patients was performed 
and the effectiveness of current local guidelines examined. Using this information, a clinical proforma was introduced along with staff education and revised treatment protocols, in conjunction with the local neurosciences centre. Prospective data were then collected using the new proforma.

Results - The majority of patients presenting to the $\mathrm{A} \& \mathrm{E}$ departments with headaches had a benign cause. For those with more serious pathology, the proforma emphasised key features to raise the clinician's suspicion; namely speed of onset, altered mental state, vomiting and photophobia.

Conclusion-The introduction of a proforma has improved history taking and accurate diagnosis, ensuring those with serious pathology get appropriate investigation, treatment and follow up. For those patients with benign headaches, who are the majority of those attending $\mathrm{A} \& \mathrm{E}$ departments, the diagnosis has been improved with treatment becoming standardised across the region.

Medical student education through teleradiology

S S Tachakra

Department of Accident and Emergency Medicine, North West London Hospitals Trust, London Radiographs of 2133 patients who were radiographed out of a total of 4000 were transmitted by medical students from a MATS (Minor Accident and Treatment Service) to a main emergency department. The students wrote down their own diagnosis and their perception of their level of knowledge before tuition.

The accident and emergency consultant in the main department taught the medical students, using the whiteboarding facility if necessary, used models, pictures and surface anatomy as necessary. Tuition was supplemented by directed personal study and other forms of leaving.
Medical students marked their past tuition level of comprehension, the quality of learning with teleradiology, and any improvements they would encourage. above.

We present how the students marked all the

Can we learn from ultrasound practice around the globe?

P Thompson, E Glucksman

Department of Accident and Emergency Medicine, King's College Hospital, London

Introduction-The role of ultrasound as performed by emergency physicians continues to be a keenly debated topic. We investigated the current use of ultrasound within three emergency departments at different levels of ultrasound expertise in London (A), Chicago (B) and Sydney (C). The objective was to determine the most appropriate use of ultrasound by emergency physicians.

Methods-Three emergency departments (A, $B$ and $C$ ) with a full range of specialist facilities were evaluated by a single doctor for one month. Each department was part of a tertiary referral teaching hospital with responsibility for trauma. Merit numbers, time for ultrasound, confirmatory investigations, quality control and department education were considered.

Results-The number of ultrasound scans performed-A 63, B 242 and C 26 corresponded to the number of ultrasound practitioners available 2, 7 and 3 respectively together with different indications. Confirmatory investigations were performed in A $72 \%$, B $45 \%$ and C $100 \%$.

Discussion-Ultrasound expertise varied between the departments with $\mathrm{C}$ concentrating on free fluid following blunt trauma. Department $B$ added abdominal pain and complicated first trimester patients and $C$ additional deep venous thrombosis exclusion.
Enthusiasm for ultrasound is increasing throughout emergency medicine, however, local issues continue to determine the actual use of ultrasound within our departments.

Emergency department thoracotomy"friend or foe"

K D Wright

Emergency Department, Wexham Park Hospital, Slough, Berkshire

Objective-Emergency department thoracotomy is an aggressive and often last ditch attempt to salvage the victim of overwhelming injury. There is probably no other procedure in the emergency department that generates as much debate as thoracotomy. This poster aims to identify via a case discussion and literature review which patients are candidates for emergency department thoracotomy and who should be performing the procedure.

Methods - Case study and literature review.

Results-The literature would support an aggressive and interventionist approach in the following patients:

(1) Penetrating chest injury with cardiac arrest at scene or en route to the emergency centre

(2) Massive hypovolaemia when external chest compressions are inadequate

(3) Cardiac arrest in asthmatics

(4) Cardiac arrest after cardiac surgery

(5) Drainage of the pericardium after positive pericardiocentesis

(6) Massive intra-abdominal bleeding to increase cerebral/cardiac perfusion

Conclusion - When performed by an appropriately trained emergency department physician surgeon the procedure is of benefit to certain groups of patients. Equally there are some patient groups identified in whom the procedure can be deemed too aggressive and is therefore contraindicated.

\section{British Association for Accident and Emergency Medicine Conference, Cambridge, 4-6 April 2000}

Cost effectiveness analysis of a minor injury unit and an accident and emergency department

R J Kendall, J Wardrope

Accident and Emergency Department, Northern General Hospital, Sheffield

Aims - To examine patient flows and cost effectiveness from a health service perspective of treatment by an accident and emergency (A\&E) department and a nurse led minor injury unit (MIU).

Methods-A cohort comparison of patients attending an A\&E department and a MIU was undertaken. In 1997 the provision of A\&E services in Sheffield were streamlined with closure of the adult $\mathrm{A} \& \mathrm{E}$ department at the Royal Hallamshire Hospital (open 8 am-8 $\mathrm{pm})$. A MIU was established at the Royal Hallamshire Hospital (open 8 am-8 pm) staffed by nurse practitioners. This change allowed an excellent opportunity to compare an A\&E department with a nurse led MIU. Two comparisons were made. In the first the overall costs of the A\&E department for the year preceding its closure were compared with those of the first year of the MIU. In the second, the minor injuries dealt with by the A\&E department for one year preceding its closure (April 1996 to March 1997, $\mathrm{n}=20$ 252) were com- pared with those dealt with by the MIU for one year ( May 1997 to April 1998, n = 13 326).

Results—For minor injuries:

1 Significantly more patients $(p=0.001)$ were discharged completely from the A\&E department $(71.6 \%)$ compared with the MIU $(51.6 \%)$

2 Significantly more patients $(\mathrm{p}=0.001)$ were brought back to returns clinics from the MIU $(12.1 \%$ in all $8.9 \%$ to the MIU and $3.2 \%$ to the $\mathrm{A} \& \mathrm{E}$ department) compared with the A\&E department (3.6\%).

3 Significantly more patients $(\mathrm{p}=0.001)$ were referred to their general practitioner from the MIU $(11.1 \%)$ compared with the A\&E department $(4.6 \%)$.

$43.8 \%$ of patients were referred immediately from the MIU to the A\&E department.

5 Significantly more patients $(p=0.001)$ were referred form the MIU to fracture clinic and eye casualty than from the $A \& E$ department.

Cost per case: The concept of an "A\&E work unit" was devised and the cost of an "A\&E work unit" for both an A\&E department and an MIU was calculated from the total data. The assumption was made that in finance terms one admission was equivalent to four non-admissions. The cost of an "A\&E work unit" for the A\&E department was $£ 26.08$ and for the MIU was $£ 31.94$.

Cost of extra referrals: From these figures the increased cost of the treatment of minor injuries at a MIU compared with an $\mathrm{A} \& \mathrm{E}$ department per patient seen was:

1 Increased cost from extra GP referrals $£ 0.45$

2 Increased cost from extra returns to MIU $£ 0.16$

3 Increased cost from extra returns to A\&E $£ 0.35$

4 Increased cost from immediate A\&E referral $£ 0.56$

5 Increased cost from extra fracture clinic referrals $£ 0.34$

6 Increased cost from extra eye casualty referrals $£ 0.11$

Total increased cost per patient seen at MIU $£ 1.97$

Summary - From these data a nurse led MIU was substantially more expensive from a Health Service perspective than a traditional A\&E department. This additional expense was partly attributable to significantly greater returns and referrals rate for the MIU compared with the A\&E department. 


\begin{tabular}{lllll}
\hline Characteristic & $\begin{array}{l}\text { NHS Direct } \\
(n=91)\end{array}$ & $\begin{array}{l}\text { Non-NHS Direct } \\
(n=232)\end{array}$ & p Value & Test \\
\hline Male sex & $50(55 \%)$ & $120(52 \%)$ & 0.622 & $\chi^{2}$ \\
Mean (SD) age (y) & $46(22.4)$ & $52.2(25.7)$ & 0.033 & t test \\
Duration of symptoms & $53(58)$ & $189(82)$ & & \\
0-24 hours (\%) & $30(33)$ & $36(15)$ & & $\chi^{2}$ \\
$1-7$ days (\%) & $7(8)$ & $4(2)$ & & \\
$8-28$ days (\%) & $1(1)$ & $3(1)$ & & \\
1 month (\%) & $3(3)$ & $8(3)$ & & \\
Manchester Triage Category (\%) & $13(14)$ & $35(15)$ & & \\
1 & $48(53)$ & $125(54)$ & & \\
2 & $27(30)$ & $64(28)$ & & \\
3 & $0(0)$ & $0(0)$ & & \\
4 & $43(47)$ & $123(53)$ & & \\
5 & $1(1)$ & $2(1)$ & & \\
Disposal (\%) & $2(2)$ & $27(12)$ & & \\
Admit to hospital & $44(40)$ & $74(32)$ & & \\
Transfer to another hospital & $1(1)$ & $6(3)$ & & \\
Discharge with follow up & & & \\
Discharge without follow up & & & \\
Did not wait & & & & \\
\hline
\end{tabular}

Whether these were appropriate returns or referrals cannot be ascertained from these data.

Intramuscular ketamine sedation of paediatric patients in the accident and emergency department

A Izquierdo- Martin, K Whitwell, J Dwyer, A Fogarty

Royal Free Hospital Accident and Emergency and Royal London Hospital Paediatric Accident and Emergency

Background - The use of ketamine for paediatric sedation in the emergency department has become increasingly popular in the United States. In the UK its use is much more limited in the accident and emergency (A\&E) setting; probably because of misinformation about its safety.

Objectives-To determine the efficacy, safety and recovery times with intramuscular ketamine sedation in paediatric patients requiring brief, painful procedures in the A\&E department.

Methods - This prospective study included all paediatric patients given intramuscular ketamine in two London teaching hospitals between September 1999 and January 2000. Inclusion in the study was determined using a detailed protocol based on a literature review. The initial ketamine dose was $4 \mathrm{mg} / \mathrm{kg}$ combined with atropine $(10 \mu \mathrm{g} / \mathrm{kg})$. A repeat ketamine dose of $2 \mathrm{mg} / \mathrm{kg}$ was used if sedation was considered inadequate after 5 to $10 \mathrm{~min}$ utes The procedure was carried out in an area with suction, oxygen and equipment for advanced airway management and by a physician who was adept at airway management. Intravenous access was not required.

Results - Thirty patients, ranging in age from 1 to 9 years old, were enrolled in the study. Mild agitation during the procedure was noted in two cases and vomiting during recovery in another two cases. Complications after discharge were noted in three cases; nightmares occurred in two cases and vomiting in one case. No patient reattended or needed treatment for these side effects.

Conclusion - Intramuscular ketamine is a consistently effective method of producing a rapid, brief period of profound sedation and analgesia in children in A\&E. While maintaining airway patency and reflexes, together with cardiovascular stability, no serious complications were noted in our study. Although a small number of patients were studied, our results are in line with larger studies reported by other emergency departments. Because of its wide margin of safety, ketamine is used regularly in operating rooms throughout the developing world with minimal patient monitoring, frequently with a single physician performing the surgery and supervising the sedation. Airway management techniques are routine skills in emergency medical practice and this provides the necessary expertise in the management of potential airway complications. We conclude that intramuscular ketamine may be administered safely by emergency physicians to facilitate paediatric procedures, with a reduction in the number of paediatric admissions and use of general anaesthesia for simple procedures.

1 White PF. Ketamine-Its pharmacology and therapeutics uses. Anesthesiology 1982;56:11936.

2 Green SM, Nakamura R, Johnson NE. Ketamin sedation for paediatric procedures. Ann Emer Med 1990;19:1033-46.

3 American Society of Anaesthesiologist. Practice guidelines for sedation and anaesthesia by non-anaesthesiologists. Anaesthesiology 1996;84: 459-71.

4 Green SM, Rothrock SG, Lynch EL, et al. Intramuscular ketamine for paediatric sedation in the emergency department: safety profile in 1022 cases. Ann Emerg Med 1998;31:688-97.

999 Cases attending accident and emergency departments-a comparison of those who did and those who did not first call NHS Direct

P Gaffney, S Crane, G Johnson*, M Playfortht

St Fames' University Hospital, Leeds, *West Yorkshire Metropolitan Ambulance Service and tAccident and Emergency, Pontefract General Hospital

Background and Aims-The NHS Direct service in West Yorkshire was launched in April 1999. An emergency (999) ambulance can be dispatched to the patient as a result of a call to NHS Direct. The aim of this study is to compare cases that had been referred by NHS Direct via the 999 service, with those who had dialled 999 themselves

Methods - The study was carried out in three accident and emergency (A\&E) department in West Yorkshire, between 1 April 1999 and 21 August 1999. WYMAS (which runs NHS Direct in West Yorkshire), released details of all patients who had been sent a 999 ambulance following a call to NHS Direct. The comparison group, was selected at random, using a random number generator, from a list of all 999 cases attending the three departments. The comparison group was 2.8 times as large as the NHS Direct group, because the total number of A\&E attendance was 2.8 times as large as the number of people who had called NHS Direct. All the A\&E records were then scrutinised for basic demographic data and the following characteristics: duration of symptoms before dialling 999, triage category on arrival in $\mathrm{A} \& \mathrm{E}$ and disposal of patient. Patients were excluded if they were dead on arrival or had been advised by their general practitioner (GP) to dial 999. The study was approved by the chairmen of the relevant Research Ethics Committees. Statistical advice was also obtained and SPSS version 8 was used for the analyses.

Results and Conclusions-During the study period 91 people, of the 28000 who called NHS Direct, were brought by emergency ambulance to these three departments. Of the comparison group (260 cases), 28 were excluded from the study. There were notable differences in presenting complaint between the two groups and in particular, trauma was less common among the NHS Direct patients $(6.6 \%)$ compared with those who had self dialled $(37.5 \%)$. Other results are shown in the table 1 .

Thus, patients who had first called NHS Direct were younger and had endured their symptoms for longer; they were less likely to be admitted, and if discharged, were less likely to have follow up arranged. These findings may partly be explained by differences in presenting complaint between the two groups. However, the $40 \%$ of patients discharged without follow up suggests that NHS Direct may be overly cautious in its selection of cases that require an emergency ambulance.

Activated charcoal: is there a role for pre-hospital administration?

S Thakore, N Murphy

Raigmore Hospital, Inverness

Introduction-Activated charcoal is now the mainstay of non-specific therapy for self poisoning in accident and emergency $(A \& E)$ departments. The position statement from clinical toxicologists and poison centres in 1997 indicated that activated charcoal should be administered within one hour of ingestion of an overdose. This target may be missed because of delays occurring before assessment by a doctor in A\&E. The aim of this study is to see if compliance with the above guidelines may be improved by the pre-hospital administration of activated charcoal.

Method-Ambulance report forms and case notes were reviewed in all patients presenting to $\mathrm{A} \& \mathrm{E}$ by ambulance after self poisoning Information was gathered using a standardised abstraction form. The times collected were: time of ingestion, time of call to ambulance control, time picked up, time of arrival in $\mathrm{A} \& \mathrm{E}$ and time seen by doctor.

Results-134 patient records reviewed to date. Fourteen have been excluded because of incomplete data on report forms or case notes. Figure 1 shows the distribution of journey times to $\mathrm{A} \& \mathrm{E}$. Figure 2 shows the proportion of people who are actually seen in the same time frame in which they are picked up. Thirty nine per cent of patients were picked up by an ambulance within one hour of overdose, only $8.5 \%$ of these were seen by medical staff within an hour of ingestion. Fifty nine per cent were picked up within two hours of ingestion of which $65 \%$ were seen by medical staff within this time frame.

Conclusions - A significant number of patients are picked up by ambulance within an hour of ingestion, however very few are then seen by someone able to prescribe charcoal within this time frame. The administration of charcoal results in few side effects provided the patient 


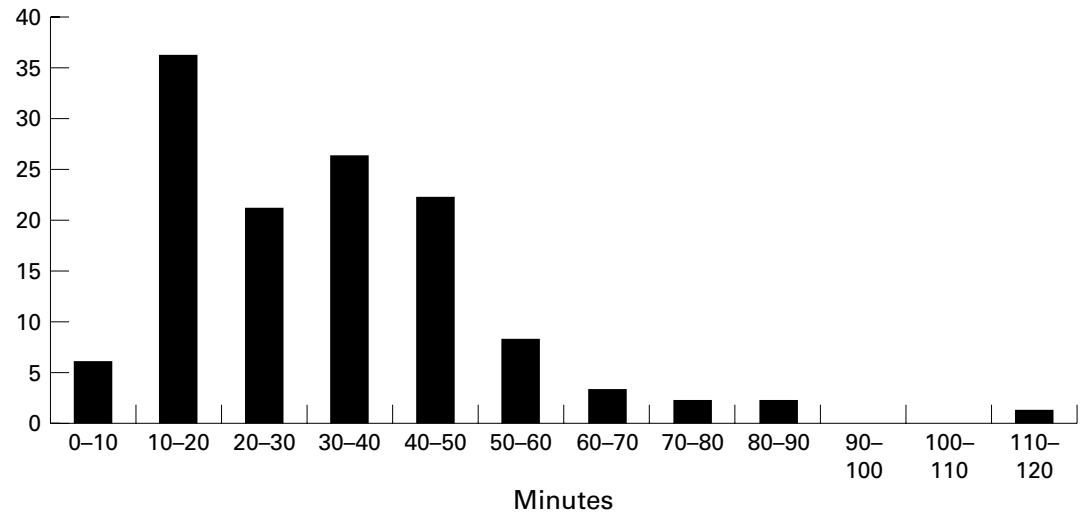

Figure 1 fourney time to A\&E.

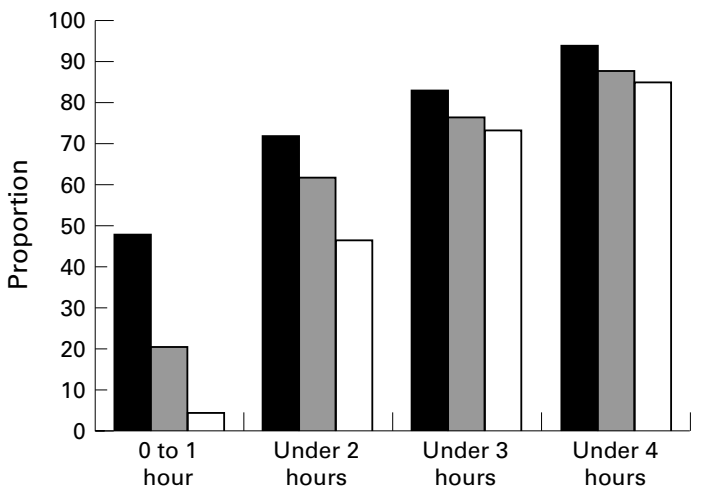

Figure 2 The proportion of patients picked up in a specific time frame who are seen in the same time frame.

can adequately protect their airway and ambulance staff could be trained in its use. The pre-hospital administration of charcoal provides an opportunity to comply with international guidelines on reducing the absorption of a potentially fatal overdose. Further studies would be necessary to investigate if this would effect clinical outcome.

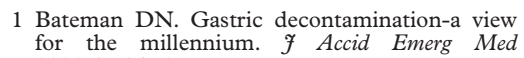
1999;16:84-6.

2 Anonymous. Position Statement: single-dose activated charcoal. Clin Toxicol 1997;35:721-41.

A study to assess the appropriate use of gut decontamination in an accident and emergency department

H Y Tiong, J J McInerney, N O'Connor, P A Evans

Leicester Royal Infirmary

Introduction-Poisoning by accidental or deliberate ingestion accounts for approximately $3 \%$ of all presentations to accident and emergency (A\&E). Historically the management of such ingestions has used three forms of gastric decontamination; gastric lavage, ipecac, and charcoal. In light of recent studies however, charcoal administration has superseded other forms of decontamination, but is not without risk. Charcoal is best given within one hour of poisoning, but does not bind all drugs, and consequently should not be given routinely to all patients. Potential adverse effects may also occur if the patient's airway is compromised. This study was instigated to determine the current use of appropriate gut decontamination in our A\&E department.

Methods-The case notes of all patients attending $\mathrm{A} \& \mathrm{E}$ with a history of deliberate or accidental self poisoning were collected over a 12 week period. The recorded administration of gut decontamination was compared with the National Poisons Information Service via the TOXBASE web site in all patient episodes. Accordingly the incidence of inapproand adverse effects was determined.

Results-368 patients were reviewed during the study and consisted of 200 differen substances ingested. There was an equal patient sex distribution, with $316(86 \%)$ cases of deliberate ingestion. Paracetamol was the predominant substance ingested followed in order of frequency, by antidepressants and benzodiazepines. One hundred and eighty $(49 \%)$ patients required admission with 63 $(17 \%)$ receiving charcoal, eight $(2 \%)$ receiving gastric lavage, and no patient receiving ipecac. Two $(95 \%$ confidence intervals $(\mathrm{CI})=$ $3.2,65)$ episodes of gastric lavage and 38 $(95 \% \mathrm{CI}=47,72)$ episodes of charcoal administration did not concur with national recommendations. Conversely in 24 (95\% CI $=4.2$, 9.5) and $18(95 \% \mathrm{CI}=2.9,7.6)$ patient episodes gastric lavage and charcoal administration respectively, should have been considered. Only 15 (4\%) patients presented within one hour with $13(20 \%)$ patients receiving charcoal thereafter. Charcoal was administered to one patient with airway compromise and there were eight $(95 \% \mathrm{CI}=5.6,23.5)$ incidences of adverse effects; one cardiac arrest secondary to aspiration, and seven episodes of vomiting.

Conclusions - The presenting characteristics of self poisoning mirror the findings of similar studies. Charcoal is the predominant decontamination method of choice but is frequently administered in contrast with national recommendations and occasionally in unsuitable clinical conditions. Gastric lavage however seems to be underused. Greater awareness of the efficacy and risks of gastric decontamination needs to be disseminated. priate administration of gut decontamination
The frequency of presentation of personal child health records to the accident and emergency department

P Doyle, I K Dukes

Accident and Emergency Department, Russell's Hall Hospital NHS Trust, West Midlands

Personal Child Health Records (PCHRs) have been issued to all new parents in the Dudley area since 1991. These are portable medical records, providing important information to parents and medical staff. In 1997, we studied the frequency of presentation of PHCRs to our accident and emergency (A\&E) department.

The parents/guardians of all children under five years of age, presenting to $\mathrm{A} \& \mathrm{E}$ with minor or moderately severe illness/injury, were offered a simple questionnaire. This questionnaire had been modified after a pilot study in the same department.

During the study period there were 640 paediatric attendances in the under 5 years group. A total of 253 questionnaires were completed. Of parents who completed the questionnaire, $98 \%$ recorded receipt of the PHCR.

Of the study group, 95\% were still in possession of the PHCR. However, at the A\&E attendance, only $13 \%$ of parents had brought the PHCR with the child. There was a variety of recorded reasons for not bringing the PHCR to A\&E. Disappointingly, $20 \%$ of respondents felt the PHCR to be of no benefit.

This study shows that PHCRs are underused, with respect to $\mathrm{A} \& \mathrm{E}$ attendances. The importance of these records should be more widely promoted.

Audit of distribution of head injuries presenting to accident and emergency department according to severity, disposal and the length of hospitalisation

T Santarius, A Kulkarni, M Choudry, S Ellis, C Park, A R MacNamara

Accident and Emergency, Birmingham Heartlands Hospital

In its report, The Royal College of Surgeons of England Working Party on the Management of Patients with Head Injuries suggested major changes, involving both its clinical and organisational aspects. Under the new guidelines, head injured patients should be managed by accident and emergency ( $A \& E$ ), neuroscience and paediatric/paediatric surgery departments. This will put substantially greater demands on A\&E personnel and equipment resources. To help to estimate the qualitative and quantitative increase in service by our $\mathrm{A} \& \mathrm{E}$ department we have conducted a descriptive study of the flow of head injured patients.

Over the period of three weeks, for each patient presenting to our $\mathrm{A} \& \mathrm{E}$ department (annually 95 000-100 000 patients) a choose n' tick audit form assessing time and mechanism of injury, symptoms, Glasgow coma scale (GCS), focal neurological deficit, radiology and disposal was filled by the examining doctor or nurse practitioner. The length of stay was determined from patients' case notes and/or hospital computer network. Minor, moderate and severe head injuries were defined as GCS 15-13 with no focal neurological deficit or skull fracture, 12-9 and less than 10 , respectively.

Over the audit period 509 patients presented with head injuries. Of these $89(17 \%)$ patients were admitted; $55(62 \%)$ to $\mathrm{A} \& \mathrm{E}$ observation unit, 17 (19\%) by paediatrics, nine $(10 \%)$ by trauma and orthopaedics (T\&O), three $(3 \%)$ to ITU, three $(3 \%)$ by 
medical teams and one patient by maxillofacial team. There were no patients transferred to neurosurgical unit during the study period. All three ITU patients had severe head injuries and died after the mean of seven days. All paediatric patients suffered minor head injuries and stayed in less than 24 hours. Similarly, the length of stay of each patient in A\&E observation unit was less than 24 hours (total 55 patient days) with only minor head injuries. Of the total nine, five $\mathrm{T} \& \mathrm{O}$ patients were admitted primarily because of head injury (two minor and three severe) and were hospitalised on average for 4.8 days (total 24 patient days). Under new guidelines these patients should be treated by the A\&E team, which would mean an increase of patient days from 55 to 79 (44\% increase). The A\&E resources for management of inpatient head injuries will have to increase at least by this proportion to meet the requirements of the new guidelines. More extensive study is in progress.

Closing the loop: feedback to accident and emergency SHOs on their referrals to hospital specialists

R Florance, G Narendra, N Burchett

Accident and Emergency Department, Queen Elizabeth Hospital, Kings Lynn

Hypothesis-Accident and emergency (A\&E) SHOs in the Anglia and Oxford region do not receive regular case specific feedback on their referrals to hospital specialists.

Methods - Telephone survey of one A\&E SHO from each hospital in the region, using a semistructured questionnaire and written protocol. The main questions asked were:

1 Do you receive regular feedback about specific patients you refer to other specialties? If so, which one(s)?

2 Do you think personal regular case specific feedback about your referrals would be useful?

Results-18 A\&E SHOs plus one Staff Grade were interviewed, one from each hospital, (response rate $100 \%$ ). Over the whole region, there were 106 hospital specialties to which A\&E SHOs could directly refer outpatient cases. However, regular case specific communication or feedback was received by the referring $\mathrm{A} \& \mathrm{E}$ SHO from only five $(4.7 \%)$ of these outpatient specialties. Over the whole region there were 237 hospital specialties to which A\&E SHOs could directly refer cases as inpatients. However regular case specific communication or feedback was received by the referring A\&E SHO from only three $(1.3 \%)$ of these inpatient specialties. Of the $18 \mathrm{SHOs}$ and one Staff Grade interviewed, 18 (95\%) felt regular case specific feedback on their referrals would be useful, with 13 of $18(72 \%)$ suggesting written feedback. Five of these $(38 \%)$ preferred a copy of the discharge summary or GP clinic letter, six (46\%) preferred a letter written specifically to the A\&E SHO, one preferred feedback via a letter written to the $\mathrm{A} \& \mathrm{E}$ consultant, and one suggested "any written feedback". All 18 doctors wanted feedback from at least one of the specialties of general medicine, paediatrics, orthopaedics/ trauma and general surgery, but feedback on selected cases was preferred to feedback on all cases.

Conclusion-A\&E SHOs in the Anglia and Oxford region do not receive regular case specific feedback on their referrals to hospital specialists. Almost all A\&E SHOs in our study would welcome it. The situation could be rectified by routinely sending them copies of clinic letters or discharge summaries.
Discussion - Written case specific feedback to $\mathrm{A} \& \mathrm{E}$ SHOs on their referrals to specialists could encourage learning, support individual continuing professional development, and improve patient management. Scrutiny of this information by the SHO's trainer could assis in competency-based assessment of the SHO's performance, and support clinical governance.

Airbag injuries in Britain-coming to an accident and emergency department near you

K Cunningham, P Burdett-Smith

Department of Accident and Emergency Medicine, Royal Liverpool University Hospital

The introduction of airbag technology has been shown to significantly reduce mortality and morbidity in motor vehicle crashes. However, the airbag like the seat belt, produces its own spectrum of injuries. With the increasing prevalence of airbags in the UK, airbag associated injuries will be seen more frequently in our accident and emergency departments. Most are minor, but in certain circumstances severe and fatal injuries can result. Hitherto, reports of fatalities have largely been from North America and the first case from the UK has just been reported. ${ }^{1}$ This case involved female driver who was fatally injured when her airbag deployed in a moderate impact frontal collision where such severe injury would not normally have been anticipated. Since then, two further fatalities have occurred in this country where the airbag has been implicated as a contributing factor. These cases have not yet been reported in the medical literature. The details of these crashes and the injuries sustained will be illustrated. The history and spectrum of airbag associated injuries will be briefly outlined. The risk-benefit ratio will be discussed and predisposing factors for airbag injury highlighted.

1 Cunningham K, Brown TD, Gradwell E, et al Airbag associated fatal head injury: case report and review of the literature on airbag injuries. $\mathcal{F}$ Accid Emerg Med 2000;17:139-42.

Analgesia use in children attending accident and emergency after an injury

S Thorp, S Mason, D Burke

Accident and Emergency Department, Sheffield Children's Hospital

Aim - To determine the pattern of analgesic administration to children attending the accident and emergency (A\&E) department after an injury.

Methods-A prospective study was undertaken over a four week period in February 1999 of children presenting to the $\mathrm{A} \& \mathrm{E}$ department after an acute injury. A questionnaire was given to the child's parents enquiring about the use of analgesia and if analgesia had not been given, why not?. Data were entered onto a database and analysed using the Epi Info 6 package.

Results - A total of 83 children were recruited to the study. Fourteen $(17 \%)$ had received paracetamol before presentation to A\&E. No child received Ibuprofen. There was no significant correlation between parental knowledge of the analgesic effects of paracetamol and pre-hospital administration $(\mathrm{p}<0.06$ Fisher's exact test). There was no significant correlation between pre-hospital administration of analgesics and the decision to give analgesia in $A \& E$ ( $p<0.53$, Fisher's exact test). Neither pre-hospital or A\&E administration of analgesia significantly correlated with the decision to admit the child $(\mathrm{p}<0.31, \mathrm{p}<0.51$,
Fisher's exact test). The most common reasons for analgesia not being administered before presentation in $\mathrm{A} \& \mathrm{E}$ were: parents did not think paracetamol would help their child (23 cases); the child was not at home when the injury occurred ( 21 cases) or that there was no paracetamol at home (13 cases).

Conclusions - There are several factors predisposing to children not receiving analgesia prehospital after an injury. The commones reasons for not giving paracetamol were that it was not available either because the child was not at home or it was not in stock at home. Interestingly although children did not receive paracetamol if it was the parental perception that paracetamol would be of no benefit to the child, knowledge of the potential benefits of paracetamol did not increase use. The decision to administer analgesia in A\&E is not influenced by the pre-hospital administration. Presumably it is the child's condition on arrival at the department that determines hospital analgesia administration. A further study is to be carried out to determine the relation between administration of analgesia prehospital and triage pain score on hospital administration of analgesia.

The impact of a dedicated district general hospital paediatric accident and emergency unit on the number of paediatric admissions to the hospital

M Mehra, V M O’Neill, A Groves

St Peter's Hospital, Chertsey, Surrey

Objective-To demonstrate the impact of a dedicated paediatrics accident and emergency unit (PAEU), which opened in March 1999, on the number of acute paediatric admissions. Design-Retrospective data analysis of paediatric accident and emergency attendances and paediatric admissions at St Peter's Hospital, a district general hospital in Surrey.

Main outcome measure-The change in hospital admission rate of paediatric patients presenting to the accident and emergency department since the opening of the PAEU. Results-Despite an $18.3 \%$ increase $(\mathrm{p}=0.00015)$ in paediatric accident and emergency attendances, a $37.6 \%$ decrease $(\mathrm{p}=0.00032)$ in acute paediatric admission was seen. The data were collected over a 10 month period (March 1998-December 1999).The data are still being collected and 12 month figures will be available at the end of March 2000.

Conclusion - The results demonstrate the beneficial effect of a dedicated PAEU in a district general hospital open to both "walk in" patients and general practitioner referrals. The PAEU with its many advantages, including a greater presence of paediatric medical staff alongside accident and emergency department medical staff and paediatric accident and emergency trained nursing staff providing focused paediatric care in an optimally configured environment, serves to reduce the number of patients admitted to the paediatric wards.

Resource implications of an outbreak of meningitis to a district hospital accident and emergency department

O O Jibuike, W D T Moody-Jones

East Glamorgan Hospital

Aim - To evaluate resource implications of meningitis outbreak to a district accident and emergency (A\&E) department.

Methods-Data from Public Health Laboratory ${ }^{1}$ show that meningococcal disease epidemics occurred over a three week period, 


\begin{tabular}{llll}
\hline & 1997 & 1998 & 1999 \\
\hline Total number seen in A\&E (study group) & 72 & 65 & 206 \\
Number discharged home from A\&E & 29 & 36 & 125 \\
Number referred to ward from A\&E & 42 & 29 & 80 \\
Number admitted by paediatricians/physicians & $19(45 \%)$ & $23(79 \%)$ & $48(60 \%)$ \\
Number sent home by paediatricians/physician & 23 & 6 & 32 \\
Cardiac arrest & 1 & 0 & 1 \\
Total number of tests & 40 & 18 & 80 \\
Total number of meningitis and septicaemia through A\&E & 0 & 1 & 4 \\
Total number of patients seen in A\&E & 491 & 506 & 634
\end{tabular}

from 23 January 1999 to 16 February 1999. Using the department's computer system, we retrieved all attendances within this period and compared with similar periods for 1998 and 1997. All patients with features suggestive of meningitis were included in the study and their A\&E case notes were manually retrieved. All patients admitted direct to ward were excluded. The laboratory investigations, referral and admission rates of these patients were recorded.

Data and results - The results are shown in table 2.

Discussion - A fourfold increase (4) in number of cases of meningococcal disease during epidemics led to a 1.3-fold increase in new attendances (128) to the local A\&E department, and a 3.2-fold increase (145) in attendance with features suggestive of meningitis, a 1.4-fold increase in drug treatments (6) and a 2.8 -fold increase (23) in referrals for admission from emergency department, a twofold increase (25) in admissions rate and a fivefold increase in investigations (66).

Conclusion-For every case of meningococcal disease (meningitis or meningococcal septicaemia) diagnosed in the $\mathrm{A} \& \mathrm{E}$ department, 54 additional cases of non-meningococcal disease conditions are seen at the local $\mathrm{A} \& \mathrm{E}$ department. This translates to an additional 18-20 hours of a Senior House Officer time. ${ }^{2}$ The case is therefore made that for every two cases of meningococcal disease, the additional workload was equivalent to one week of doctor's time.

1 Annual Report Bro Taf Health Authority. Meningitis and meningococcal disease 1999. Cymru web. Wales.nhs.uk 2 BAEM. Report of the working party on The Way
Ahead 1998. London: British Association of Accident and Emergency Medicine.

A development and evaluation template for minor injuries telemedicine J Benger

Tewkesbury Hospital, Gloucestershire Introduction-Minor injuries telemedicine aims to support minor injuries units and peripheral accident and emergency (A\&E) departments from larger A\&E centres through the use of telemedicine. Recent funding from the $\mathrm{A} \& \mathrm{E}$ modernisation programme, along with many local initiatives, have led to a sharp increase in the number of centres experimenting with minor injuries telemedicine. A template has been designed to assist such developments and provide a framework, based on current best evidence, that will guide new users through the development and evaluation of this new technique.

Development phase-The development of a minor injuries telemedicine system has been broken down into eight distinct stages:

Stage one: two essential starting questions

Stage two: alternatives

Stage three: staff involvement

Stage four: prepare for change

Stage five: beware of sharks!

Stage six: count the cost
Stage seven: install the system

Stage eight: training, training, training

Evaluation phase - As soon as the system starts to be used the evaluation process should also begin. A written contemporaneous record needs to be made of the consultation at both the remote and central site, and for the purposes of formal evaluation a sample record sheet is described. The essential information required in the evaluation process is as follows:

1 Date and time of call.

2 Patient identification.

3 What would have happened to the patient had telemedicine not been available.

4 Name and grade of staff at both ends of each teleconsultation.

5 Nature of the problem requiring teleconsultation.

6 Patient outcome.

7 Time required for call.

8 Notes and comments.

Optional information includes whether the patient was present during the consultation, whether a radiograph was transmitted and satisfaction scores for patients and staff.

The reckoning-For any new healthcare development audit and formal review are mandatory. Techniques for clinical and economic evaluation are described, along with the experiences of several $\mathrm{A} \& \mathrm{E}$ departments in which minor injuries telemedicine has recently been adopted and this evaluation template used.

\section{Respiratory rate measurement at the} double

P Burdett-Smith, A Breakell, C TownsendRose, A Fisher

Royal Liverpool University Hospital

The respiratory rate is a useful clinical indicator of disease. It is affected by a range of conditions from those directly affecting the respiratory tract, ${ }^{1}$ to metabolic disturbance, cerebral pathology and trauma. It is one of the parameters in a number of scoring scales, including the revised Trauma Score $^{2}$ and $\mathrm{APACHE}^{3}$ and is a prognostic sign in the WHO classification of acute respiratory disease. Yet it is commonly omitted during initia assessment and is poorly recorded even when shown to be clinically necessary. It is the only one of the vital signs that cannot yet be easily recorded electronically. ${ }^{4}$

Two groups working independently in the accident and emergency (A\&E) department of the Royal Liverpool University Hospital have developed electronic devices to measure respiratory rate in conscious spontaneously breathing patients.

The Royal Liverpool respiratory rate meter uses Titanate-Zirconate ( $\mathrm{Ti}-\mathrm{Zi}$ ) ceramic films, deposited on a metallic substrate to generate measurable pyro-electric voltage when stimulated by temperature changes during inspiration and expiration. A $1 \mathrm{~cm} 2$ film is inserted into the oxygen face mask and the current is converted to a digital reading that is averaged every five breaths to give a constantly updated measure of respiratory rate.

A prototype was evaluated in the laboratory before clinical evaluation in the $\mathrm{A} \& \mathrm{E}$ department and the recovery ward in the operating theatre suite. The device was developed with the help of a grant from the North West research and development office and was a collaboration between the departments of $\mathrm{A} \& \mathrm{E}$ medicine and the university department of clinical engineering.

The "respimeter" was developed by two of the senior staff independent of the department with private finance and the various components been patented. It relies on movement of a polystyrene ball within a tube to register inspiration and expiration, which is detected by a movement sensor attached to a digital readout. Clinical evaluation was carried out in the respiratory laboratory and the device was shortlisted for a local innovation award.

Both designs are undergoing commercial development with a view to marketing.

This presentation will describe the mechanism of action and development of both devices and will in particular describe and emphasise the different routes available for commercial realisation of a technological solution to a common problem.

1 Gravelyn TR, Weg JG. Respiratory rate as an indicator of acute respiratory failure. $\mathcal{F} A M A$ 1980;244:1123-5.

2 Champion HR, Sacco WJ, Carnazzo AJ. The Trauma Score. Crit Care Med 1981;9:672-6.

3 Knaus WA, Wagner DP, Draper FA, et al. The APACHE III prognostic system: risk prediction of hospital mortality for critically ill hospitalised adults. Chest 1991;100:1619-36.

4 Burdett-Smith P. Always check the respiratory rate. BMF 1997;314:1549.

Evaluation of an ambulance-emergency department telemedicine link: the Blackpool experience

C Brookes, N Harrop, A Mitchell*

Blackpool Victoria Hospital and ${ }^{\star}$ Lancashire Ambulance Service

Telemedicine is becoming increasingly accepted as a valuable adjunct to patient assessment. Within Lancashire, a joint project has been developed between the ambulance service and the accident and emergency department at the Victoria Hospital in Blackpool (a busy unit treating 85000 new patients each year.) This involves generating television pictures by compressing the analogue output from four colour video cameras into digital format over the GSM telecommunications cellular network. The pictures are transmitted to a personal computer equipped with a modem within the emergency department. Direct voice communication is via an additional GSM cellular telephone. ${ }^{1}$

Fundamental to the evolution and development of telemedicine is the supposition that use of this technology will improve outcomes. ${ }^{2}$ As such, a pilot project is presented whereby initial assessment of the Blackpool telemedicine link is described. Fifty consecutive transmissions were evaluated by the despatching ambulance paramedic and the receiving emergency department doctor using a visual analogue scale. Interobserver error was eliminated by the same personnel being involved in each transmission.

Reliability of equipment and clarity of communication was excellent with none of the transmissions being affected by technical difficulties.

The main advantage demonstrated by use of the link was the ability to perform an accurate assessment of the personnel, equipment 
and area within the emergency department necessary for the arrival of each patient. This was found to be superior to wireless communication in all cases emphasising the benefit of telemedicine and clear voice communication over ambulance radio transmission alone.

This is particularly relevant to the emergency department in Blackpool because the current layout of the unit, coupled with the number of patients can often be stretching the capacity of the department to the limit. The ability to have the clearest possible picture of an expected patient was found to result in a significant improvement in the logistical organisation of the department. It is possible though that the ability to communicate clearly and effectively with the paramedic using a digital cellular telephone was the predominant feature. A further project to investigate this hypothesis is now planned.

1 Curry GR, Harrop N. The Lancashire telemedicine ambulance. Fournal of Telemedicine 1998;4:231-8.

2 http://www.sadiel.es./europa/hector

The BAEM web site-playing a role in international emergency medicine

J Ryan

Accident and Emergency Department, Royal Sussex County Hospital, Brighton

Introduction-The BAEM web site was formally established in 1998. It contains a number of useful documents and information about emergency medicine in the UK as well as facilitating worldwide electronic communication in emergency medicine.

Aims - The aim of this study was to investigate use of the web site by non-UK residents with a view to modifying the web site to encourage more usage by non-UK emergency staff.

Methods - A statistical software package was linked to the BAEM web site. Data recorded included the most popular pages visited, the numbers of visits to each page per month, the country of origin of people accessing the site and the referral source where access was from another web site.

Results-The site is being visited with increasing frequency. There are more than 1000 different visitors each month viewing in excess of 30000 pages. Most visitors access the site during the normal working week. The pages accessed most frequently are the home page, the publications page and the academic page. In addition a number of valuable documents including the millennium paper and the broadsheets are being accessed with increasing frequency.

Discussion - The BAEM web site is being accessed increasingly by people from overseas. The popularity of the academic site and the publications page suggests that the BAEM should continue to publish guidelines and statement papers. The number of users from eastern Europe, Australasia, the US and Latin America may provide BAEM members with opportunities for networking, addressing manpower issues and collaborative research via the web site. The use of the site from people in non-English speaking countries suggests that there is a need for a mirror site in other languages particularly Spanish. It also allows us the opportunity to market the fournal of Accident and Emergency Medicine in countries where emergency medicine is still a fledgling specialty.
A study of minor injuries care in accident and emergency department versus minor injuries unit

M Sakr, J Angus, A Saunders, J Wardrope Accident and Emergency Department, Northern General Hospital, Sheffield

Aim - To investigate the processes of care and treatment provided to patients with minor injuries presenting to accident and emergency department $(\mathrm{A} \& \mathrm{E})$ and compare it with similar group of patients presenting to the same hospital after replacement of the departmen with a nurse led minor injuries unit (MIU).

Patients - 1500 adult patients presenting with minor injuries to $\mathrm{A} \& \mathrm{E}$ department, compared with similar 1355 patients presenting to the MIU that replaced the department.

Setting-A large urban teaching hospital A\&E department in 1996, and its successor MIU in 1997.

Design-A prospective study with double assessment of the patient (clinical and researcher). These two assessments were compared. On completion of the study the groups were compared.

Results-These are the results from analyses of 1440 patients from A\&E department, and 1315 from MIU. The remaining will be available soon. When compared against an experienced A\&E clinician, there were statistically significant differences in the accuracy of medical history taking in favour of nurse practitioners working in the MIU. Waiting and department times were also significantly shorter $(\mathrm{p}<0.0001)$. On the other hand there was a statistically significant difference in the accuracy of examination in favour of doctors working in the A\&E department. Nurses also tended to arrange more follow up than doctors $(p<0.0001)$. There were no differences in documenting mechanism of injury, treatment, arranging follow up or radiological use and interpretation.

Conclusions-The establishment of nurse practitioner led MIU has provided fast track for patients presenting with minor injuries. The quality of clinical care was as good as that provided by doctors.

Pre-registration house officers in accident and emergency medicine-a step forward to the past

M R James, J D Whittaker

Royal Preston Hospital, Lancashire

Pre-registration house officer posts in acciden and emergency (A\&E) medicine were discontinued 20 years ago. We were aware of the fact that many pre-registration house officers were becoming dissatisfied with the learning experience during that year of their training. We felt that $\mathrm{A} \& \mathrm{E}$ medicine could offer an improved experience for them. After discussion with our local postgraduate dean, she agreed to fund a pilot project for a year. The first pre-registration house officers took up post in August 1998. This has subsequently been continued and expanded. We will present why the pilot was set up, how it was se up and the impressions of the pre-registration house officers and the senior medical staff after its first year of operation. In addition to general impressions our pre-registration house officers completed a questionnaire covering their educational supervision, their clinical knowledge and skills, the teaching they received, the supervision they received and their role in each of their jobs (they all rotated through pre-registration house officer posts in $\mathrm{A} \& \mathrm{E}$, medicine and general surgery). The questions in the questionnaire have all been drawn from previously published papers on the pre-registration year so that in due course, when the numbers are greater, direct comparisons can be made. Some of the salient points are detailed below:

- Two thirds not satisfied with their educational supervision in surgery (all satisfied in $\mathrm{A} \& \mathrm{E}$ and medicine)

- Two thirds did not receive an induction in surgery and one third in general medicine (all did in A\&E).

- Two thirds received no shopfloor teaching in surgery (all in A\&E and medicine).

- A third of them felt that there were problems with senior supervision in medicine and similar numbers in surgery (all satisfied in $\mathrm{A} \& \mathrm{E}$ )

- A third were dissatisfied with their clinical experience in surgery (all satisfied in medicine and $\mathrm{A} \& \mathrm{E})$.

- They were all asked on the teaching they received in a spectrum of skills and knowledge covering all the specialties. This covered 24 separate topics. Scoring each topic satisfactorily covered in each specialty then the average score per doctor in $\mathrm{A} \& \mathrm{E}$ was 19 , in medicine 16 and in surgery 7 . A detailed breakdown of this will be provided in the presentation.

Having only had three pre-registration house officers go through the complete scheme so far, the above results are not statistically valid but do show some interesting trends.

This project has generated an enormous amount of interest from around the country and we are aware of several other similar schemes currently being set up. We therefore feel that this innovation urgently requires accurate dissemination at a national meeting both to ensure that schemes are set up appropriately and also to stimulate discussion.

An emergency admissions unit-a threat or an opportunity

D G Ferguson

Central Sheffield University Hospitals Trust

In May 1997, the accident and emergency (A\&E) services left the Central Sheffield University Hospitals Trust and moved to the Northern General Hospital Trust, Sheffield. The emergency workload at the CSUH dropped from $60 \%$ of the city's activity to $30 \%$.

We built a unique emergency admissions unit capable of treating all emergencies other than trauma, there is a dedicated nursing staff but the medical and surgical teams are the on call teams of the day and they have sole responsibility for the patients. Our patients are secondary referrals from general practice, our intention was to make it as easy as possible for general practitioners to admit patients into hospital or to receive an emergency opinion, this is organised through our Bed Bureau. The 30 bed unit is where the most acutely ill, medical and surgical patients are treated unti stabilised and then they are transferred to available beds within the hospital, the majority being transferred within a 24 hour period.

We want to extend our direct admission protocols from the current chest pain, and shortly to be developed gynaecological bleed protocol, to capture patients with respiratory and gastrointestinal bleed problems.

1 Who should manage such a unit? Is it the province of the A\&E consultant.

2 Is there a training opportunity for SpRs in A\&E medicine?

3 Are such units a threat to local $A \& E$ department, as they may cherry pick selected emergencies? 
Table 3 Process of care and radiological clinically important errors

\begin{tabular}{lllll}
\hline & $A \mathcal{E} E(n, \%)$ & $M I U(n, \%)$ & $\chi^{2}$ & $p$ Value \\
\hline History, mechanism of injury & $2(0.1)$ & $1(0.07)$ & & $\mathrm{p}=1$ \\
Past, medical history & $32(2.2)$ & $5(0.4)$ & 17.6 & $\mathrm{p}<0.0001$ \\
Examination & $28(1.9)$ & $43(3.3)$ & 4.81 & $\mathrm{p}=0.03$ \\
Treatment, advice & $60(4.2)$ & $42(3.2)$ & 1.8 & $\mathrm{p}=0.2$ \\
Follow up & $48(3.3)$ & $42(3.2)$ & 0.04 & $\mathrm{p}=0.8$ \\
Total number of patients analysed & 1440 & 1315 & & \\
Radiographs requested & $240(16.7)$ & $197(14.9)$ & 1.46 & $\mathrm{p}=0.2$ \\
Radiological interpretation & $13(0.9)$ & $10(0.8)$ & 0.17 & $\mathrm{p}=0.7$ \\
Referred & $157(8.1)$ & $228(17.3)$ & 23.7 & $\mathrm{p}<0.0001$ \\
\hline
\end{tabular}

4 Do hospitals perish when they lose their A\&E departments?

1 Ferguson DG. Managing our survival-an emergency admissions unit. Clinician In Management; 1997:6.

Feasibility study of rapid diagnosis and treatment centre

R D Hardern, A Taylor, R Shelton, A Lester

The General Infirmary at Leeds

Objective-To estimate the impact of opening a rapid diagnosis and treatment centre (RDTC).

Design-Retrospective review of accident and emergency (A\&E) cards.

Setting-Urban A\&E department with 100000 new patients annually.

Subjects-A\&E records were reviewed for all adults presenting over 16 consecutive days

Interventions-Clinical records were compared with predetermined RDTC management policies that were developed for 28 conditions. Average length of stay (both mean and median) for specific conditions were determined from the hospital Patient Administration System. Anticipated length of stays were calculated for each RDTC protocol and estimates made of the proportion of patients who would be discharged from hospital at the end of each protocol (based on published research where available)

Main outcome measures-For each condition with an RDTC protocol the anticipated bed occupancy if the RDTC had been operational was calculated. This was compared with the bed occupancy based on historical data (with no RDTC). The difference between these was calculated.

Results-During a 16 day period there were 4165 attenders. Of these 225 (5.4\%) were felt to fit the entry criteria for RDTC management. The size of RDTC that would be required to accommodate patients promptly was 10 beds, though expected bed occupancy on RDTC was six to eight at most times. The average number of ward beds that would be freed by the RDTC was estimated to be 16-30 (dependent on whether mean or median was used as "average"). If an RDTC had been operational during the period of the study the average overall daily bed saving would have been between 6 and 20 beds. The greatest expected bed savings were from patients presenting with deliberate self harm, exacerbations of COPD, chest pain (with low risk of acute coronary syndrome) and community acquired pneumonia.

Conclusions-Managing patients with a limited number of (high volume) conditions whom fit strict entry criteria for a limited time (24 hours maximum, though less for many conditions) is expected to reduce bed occupancy without increasing clinical risk.
Admission avoidance and early discharge of acute hospital admissions: an acciden and emergency based scheme

C Hardy, D Whitwell, B Sarsfield, C Maima-

Department of Accident and Emergency Medicine, Lifespan Community NHS Trust Addenbrooke's Hospital, Cambridge

Study-We report the results of a one yea pilot project on admission avoidance and early discharge of acute hospital admissions: an accident and emergency (A\&E) based scheme. This has been achieved by means of two separate teams, one in hospital and the other in the community, working closely together at the interface between primary and secondary health care.

Design-A purpose designed admission avoidance (AA) team was established in the A\&E department, and a target group of patients identified whose admissions might be avoided or curtailed. A rapid response community team (RRCT) based in Cambridge was also established to provide basic health care to patients in their homes after discharge from hospital. The key elements of our project were rapid assessment, careful selection of patients, early decision making at senior level, and close liaison with the community team.

Results-During the first 12 months of the project 785 patients were assessed and assisted in their discharge by the AA team. Altogether 257 patients were discharged to the care of the RRCT. Some 136 of 257 (79\%) were comparable to the control group, in their diagnoses and care needs, and had an average hospital stay of 1.2 days compared with the 6.3 days before the project. The remaining 121 patients were not directly comparable bu were supported by the teams because the benefits were clear and exclusion would have been unethical. These patients had an average length of hospital stay of seven days. The average length of stay under the care of the RRCT was seven days. Three patients were readmitted to hospital for unrelated reasons and the remaining became independent or returned to their pre-admission level of dependence. A patient satisfaction survey for the first three months of the project revealed that $85 \%$ of patients were "satisfied to very satisfied" with their care. The RRCT had also looked after additional 194 patients from other sources, including postoperative orthopaedic early discharges from an adjacent hospital.

Conclusions-These results indicate that a coordinated approach to the identification of patients suitable for immediate or early discharge, and to short-term domiciliary support that aims rapidly to restore previous levels of independence, can reduce the burden of acute admissions to hospital without reducing quality of care or patient satisfaction. The scheme has now been established on a permanent basis and extension of this strategy to other patient groups is under evaluation.

Troponin $\mathrm{T}$ : the answer to chest pain in accident and emergency?

E Worthington, J Hollingsworth, L Jaffey, S Saltissi, P Mullins, E Manning, A Stot Departments of Accident and Emergency, Cardiology and Clinical Biochemistry, Royal Liverpool University Hospital

Objectives - The introduction of troponin $\mathrm{T}$ as the primary biochemical marker of myocardial damage: its negative predictive value as part of a chest pain care pathway in exclusion of an acute myocardial infarction and significant ischaemia in patients presenting to the accident and emergency (A\&E) department with chest pain.

Methods-This was a prospective study of consecutive patients with chest pain of possible cardiac origin presenting to an urban teaching hospital A\&E department. Their assessment was as per the multidisciplinary chest pain care pathway including repeated ECGs and a troponin T level at 12 hours after the onset of chest pain. All patients discharged from the A\&E department without review by the medical on call team were followed up for 30 days.

Main outcome measures-Length of hospital stay, all cause mortality, diagnosis of AMI, admission to hospital, further attendance at an $\mathrm{A} \& \mathrm{E}$ department with complaint of chest pain or other cardiac symptom.

Results - In the three month study period 206 patients presenting with chest pain were discharged from the $\mathrm{A} \& \mathrm{E}$ department. The average length of stay was 0.7 days (range $0-3)$. One patient was re-admitted with AMI, he later died following urgent angioplasty. Two others were re-admitted but both were discharged in $<48$ hours. Four patients re-attended at $\mathrm{A} \& \mathrm{E}$ but again were suitable for early discharge.

Conclusion-As part of a chest pain care path way, troponin $\mathrm{T}$ measured at 12 hours after the onset of pain is a useful tool in excluding AMI and significant ischaemia safely allowing shorter hospital admissions than in previous practice.

Peer review: demonstrating quality in accident and emergency

J Porter, S Nash^, M Shalley†

BAEM, ${ }^{\star}$ Bromley Hospital and +Birmingham Heartlands Hospital

Aim of study-To determine whether peer review would be of value in accident and emergency (A\&E) medicine in terms of:

- providing support to colleagues

- spreading good practice

- contributing to requirements for audit and clinical governance

- contributing to the continuing professional development of those taking part.

Method-All A\&E consultants in North East Thames and the West Midlands were invited to take part and over $80 \%$ volunteered. They were randomly selected to act as visitors or to receive a peer review of their department. All visitors were from the opposite region but were allocated as closely as possible to hospitals comparable to their own. Visitors were asked to approach the visit as an appraisal not an assessment but clear documentation was provided to maximise consistency and minimise the workload of report preparation

There were four components to the review: 
- collection of data on the workload and resources of the department

- a record of departmental performance against quantitative standards

- an appraisal by the visitors of the quality of departmental care across a range of areas, as they perceived it by observation and discussion with staff

- an appraisal of the department by other hospital departments and outside agencies by questionnaire

All those involved were asked to evaluate the process and will be asked a year later whether any change resulted.

Results - 12 visits completed by January 2000 form the basis of this presentation. Results highlight the extent of variation in A\&E workload and resources and the difficulty in obtaining reliable data, particularly for clinical audit. The process seemed to be of greatest value to the visitors but evaluation from all those involved was overwhelmingly positive. Participants have been able to suggest a range of improvements to details of the scheme but the framework seems sound and we believe it would be valuable as a nationwide programme to demonstrate the specialties commitment to quality care.

Does risk stratification apply to British accident and emergency patients presenting with acute syncope?

S Crane

Yorkshire Rotation

Background and Aims - Syncope is defined as a sudden, temporary loss of consciousness from which the patient makes a complete and spontaneous recovery. Following a review of the literature (which consistently points to heart disease as being the major prognostic factor in patients with syncope), the American College of Physicians (ACP), published a position paper that includes disposal guidelines for syncopal patients. ${ }^{1}$ The guideline divides syncopal patients, (based on easily obtainable data such as age, history of presenting complaint, examination, past medical history and ECG changes), into those who should be admitted, those in whom admission is often indicated and the remainder. I have called these high, moderate and low risk groups respectively. The aim of this study was to find out if this risk stratification is applicable to British practice.

Methods - Study data were collected in the accident and emergency (A\&E) department of the Leeds General Infirmary (LGI) over an eight week period beginning on 2 November 1998. All A\&E records were hand searched by the same reviewer to identify those with a presenting complaint (written on the front of the record) of either collapse, collapse query cause, faint, syncope, fit or fall. Such records were further scrutinised to identify patients with a clear history of temporary loss of consciousness (either from the patient or a witness) but who had recovered spontaneously. Exclusion criteria were as follows: age $<16$ years, GCS $<15$ or focal neurological signs when examined by the A\&E doctor, a clear seizure in a known epileptic, patients intoxicated with alcohol or other drugs and those "found on floor" (that is, no clear history of temporary loss of consciousness). All selected records were then looked at in detail to determine basic demography, past medical and drug history. Each patient was stratified in terms of risk using the ACP Guidelines, and their diagnosis and disposal after A\&E assessment was determined. The general practices of all patients were contacted
Table 4

\begin{tabular}{lll}
\hline $\begin{array}{l}\text { Risk as per ACP } \\
\text { Guidelines (traceable } \\
\text { patients only) }\end{array}$ & $\begin{array}{l}\text { Number } \\
\text { dead at one } \\
\text { year }(n=24)\end{array}$ & $\begin{array}{l}\text { Incidence of } \\
\text { death within } \\
\text { one year }(\%)\end{array}$ \\
\hline High $(\mathrm{n}=44)$ & & \\
$\quad$ Admitted $(\mathrm{n}=29)$ & 12 & 41 \\
$\begin{array}{l}\text { Discharged }(\mathrm{n}=15) \\
\text { Moderate }(\mathrm{n}=57)\end{array}$ & 4 & 27 \\
$\quad \begin{array}{l}\text { Admitted }(\mathrm{n}=31) \\
\text { Discharged }(\mathrm{n}=26)\end{array}$ & 5 & 16 \\
$\begin{array}{c}\text { Low }(\mathrm{n}=88)(\mathrm{n}=10) \\
\text { Admitted }(\mathrm{n}=10)\end{array}$ & 0 & 12 \\
Discharged $(\mathrm{n}=78)$ & 0 & 0 \\
\hline
\end{tabular}

exactly one year later to determine whether the patient was still alive. The Chairman of the LGI Research Ethics Committee approved the study.

Results and Comment-The total number of patients included in the study was $210(1.75 \%$ of all adult $\mathrm{A} \& \mathrm{E}$ attenders). There was a bimodal distribution in terms of age with $41 \%$ younger than 44 years, $14 \%$ aged between 45 and 65 years and $45 \%$ older than 65 years. Sixty two per cent were women. Forty seven $(22 \%)$ of patients were stratified into the high risk group, 63 patients (30\%) into the moderate risk group and 100 patients $(48 \%)$ into the low risk group as defined by ACP Guidelines. A total of 189 patients could be traced at a year of whom $24(12.7 \%)$ had died. Other results are shown in table 4.

Forty two per cent of the entire sample were not assigned a diagnosis after their assessmen in the $\mathrm{A} \& \mathrm{E}$ department. This study has shown, however, that syncopal patients can be stratified in terms of risk and that this accurately reflects subsequent prognosis. As it is known that syncopal patients with heart disease are at greater risk, better decisions regarding subsequent disposal, follow up and treatment of these patients may be made. It remains unclear from this study, however, if admission to the hospital improves outcome.

1 Linzer M, et al. Diagnosing syncope part 2: unexplained syncope. Ann Intern Med 1997;127:7686.

Headaches in the accident and emergency department: towards a decision support system using Bayesian graphical modelling

K Lambert, N Halford, M Rickards, $\mathrm{R}$ Thom son ${ }^{\star}, \mathrm{F}$ Coolent, D Woofft

Queen Elizabeth Hospital, Gateshead, ${ }^{\star}$ Newcas tle University and tDepartment of Mathematical Sciences, University of Durham

Introduction-Decision support systems are becoming increasingly used in medical practice. Subarachnoid haemorrhage is one condition in which initial misdiagnosis may lead to avoidable morbidity and mortality, particularly in patients in whom headache is the only presenting symptom. A decision support too for patients with headache may therefore be of practical use to the inexperienced clinician. One such method is Bayesian graphical modelling; existing knowledge is made explicit as an expression of "prior belief", which is then modified by the addition of new patient information

Aim - To demonstrate the theoretical application of Bayesian graphical modelling to the problem of patients attending the accident and emergency department with headache.

Method-Expert opinion and structured searches of the medical literature were undertaken to construct a visual representation of the diagnostic process and to select relevan aetiological factors, symptoms, signs and differential diagnoses. Each factor becomes a node within the model, with unidirectional links denoting the existence of a relation between nodes. Every relation is assigned a conditional probability, derived where possible from the literature. Where structured searching techniques fail to identify relevant literature, expert opinion or a "best guess" is used to assign these probabilities. Prospective data collection must be standardised to generate information in a form that can be entered in the graphical model.

Conclusion - The potential benefits and diffculties of this approach are discussed.

Transient synovitis; is there a need to aspirate hip joint effusions?

J Skinner, T F Beattie, S Glancy

Accident and Emergency Department, Royal Hospital for Sick Children, Edinburgh

Introduction - There remains controversy as to whether children with hip effusions should undergo hip aspiration to rule out sepsis.

Objective-The purpose of this study is firstly to determine whether there is a need to aspirate hip joint effusions detected on ultrasound in patients with clinical transient synovitis and secondly to identify the natural history of these effusions.

Methods - This is a prospective ongoing study of children with hip joint effusions. All patients presenting to the accident and emergency (A\&E) department with a limp undergo standard clinical examination, bilateral hip ultrasound, temperature recording and laboratory estimation of FBC and erythrocyte sedimentation rate. Sepsis is suspected in patients with raised temperatures or abnormal blood results and they are referred to the orthopaedic team. All other patients with hip effusions were managed as outpatients within the A\&E department with further clinical examination and ultrasound at seven days and then again at 14 days if symptoms or an effusion persisted.

Results-Between September and December 1999 there have been 15 patients with clinical transient synovitis and hip joint effusions. No child underwent hip aspiration and no cases of sepsis were missed. The median size of hip effusion at presentation was $9 \mathrm{~mm}$ (range $3-11 \mathrm{~mm}$ ) with $52 \%$ being right sided and $2 \%$ bilateral. At seven days $70 \%$ of patients had a normal clinical examination with no detectable effusion on ultrasound. At 14 days $26 \%$ still had an effusion detectable on ultrasound but they were all pain and limp free and their effusions were reducing in size.

Conclusions-These results support the known benign nature of transient synovitis and that it will settle with conservative treatment. Routine painful hip aspiration is generally unnecessary, as cases of sepsis should be detected by clinical examination supported by laboratory investigation.

The Royal College of Surgeons working party report on the management of head injuries: a study to assess its impact on accident and emergency department workload

T Lloyd, J J McInerney, N O’Connor, G C Bodiwala

Introduction-The recent Royal College of Surgeons working party report by Professor Galasko recommends that all head injuries requiring a period of observation for up to 48 hours should be admitted to an accident and emergency (A\&E) short stay ward. This has obvious training, staffing and economic con- 
siderations. The current practice within our $\mathrm{A} \& \mathrm{E}$ department is to utilise a short stay ward for such patients, excluding those with skull fractures or positive CT scans. Consequently a study was undertaken to assess the impact of implementation of the Galasko report on our department's workload.

Methods-A retrospective analysis was undertaken of all patient case notes of patients with head injury over a one year period. Admission criteria to the $\mathrm{A} \& \mathrm{E}$ ward consisted on the presence of one of the following;

1 Confusion or any depression of the level of consciousness at the time of examination.

2 Neurological signs and/or severe headache and vomiting.

3 Difficulty in assessing the patient, for example, alcohol, epilepsy.

4 Other medical conditions, for example, haemophilia, patients on warfarin.

5 The patient's social conditions or lack of a responsible adult/relative.

Patients with skull fractures or under 16 years of age were admitted under the general surgeons, while patients with positive CT findings were discussed with the regional neurosurgical unit and transferred as appropriate. Results-Over one year 433 patients presented with head injuries requiring admission. A total of 178 patients were admitted under the care of the general surgeons (65 requiring admission to the ICU). Twenty three of these patients were transferred to the regional neurosurgical unit. The $\mathrm{A} \& \mathrm{E}$ ward was closed for 42 days because of staff shortages, but when open accepted 255 head injured patients (mean $<1$ per day). A total of 232 A\&E ward notes were available for analysis. Some 163 men and 69 women with a mean age of 41.9 years (range 16-94 years) were admitted. The aetiologies of head injury were; falls (35\%), assaults $(32 \%)$, road traffic accidents $(22 \%)$, and miscellaneous (11\%). The reasons for admission were; adverse clinical symptoms and signs $(68 \%)$, inability to assess $(18 \%)$ and social/other reasons (14\%). Mean length of admission was 14.3 hours (range 6-40 hours) with eight patients self discharging. Fifteen patients deteriorated after admission necessitating a CT scan, although none required neurosurgical transfer. Twenty three patients required transfer to other wards because of protracted social reasons $(2.6 \%)$, persisten head injury symptoms $(2.6 \%)$ or for other specialist treatment $(3 \%)$. There were no deaths or adverse sequelae.

Discussion-Although the management of head injuries within our $A \& E$ is safe, the presence of 24 hour on site middle grade cove and a fully staffed ward nearby, is not feasible in most A\&E departments. Furthermore, this study reveals that our own short stay ward is frequently unavailable, and that patients often require care beyond 48 hours, necessitating admission under the care of the general surgeons (not including those admissions for skull fractures or post-neurosurgical rehabilitation). Our experience suggests that the nationwide implementation of the Galasko report is unattainable unless additional resources are available, and clear guidelines developed.

An evaluation of emergency department lower limb plethysmography in the diagnosis of venous thrombosis

J Ryan, S Barden, B Tidey

Royal Sussex County Hospital, Brighton

Aims - The aim of the study was to evaluate the impact of introducing lower limb plethysmography for the diagnosis of deep vein thrombosis (DVT) in the emergency department.

Methods-A plethysmographic venometer was used in the emergency department to assess patients with a clinically suspicious DVT. The investigation was available 24 hours a day and performed by radiographers. Any patient with a clinical suspicion of a DVT had an initial diagnostic test performed using the venometer. Patients with negative venometry were discharged. Any patient with positive venometry underwent Doppler studies for further evaluation and were treated appropriately. The emergency department computer system was searched for three months after their test for unscheduled return visits by those patients who had had a "normal" venometer result.

Results -737 venometer studies were performed on emergency department patients during a 14 month study period. Full data were available in 684 cases. A positive result was obtained in 205 (33\%) cases and a negative result in $479(67 \%)$ cases. There were 76 false positive tests, defined as those cases where a venometer gave a positive result but Doppler ultrasound investigation was normal. Of the 479 patients with normal venometry no patient returned with symptoms or signs of thrombotic disease within three months of the initial presentation. Thirty nine patients with an initial negative venometry had furthe diagnostic tests performed that showed a positive Doppler in three cases and a high probability V-Q scan in two cases.

Conclusions - The venometer is a non-invasive tool that can provide a rapid and safe result in the emergency department for most patients where a diagnosis of lower limb thrombotic disease is suspected. Its use has significant cost saving implications particularly where the patient presents out of hours as the alternative is hospital admission until a Doppler test can be performed. Patients with a high clinical suspicion of venous thrombosis and an initial negative venometer should have a repeat venometer performed at a later stage. 